Acta Crystallographica Section A

Foundations of

Crystallography

ISSN 0108-7673

\section{Report of the Executive Committee for 2011}

\section{Twenty-Second General Assembly and International Congress of Crystallography}

The Twenty-Second General Assembly and International Congress of Crystallography were held at the Municipal Congress Centre, Madrid, Spain, 22-30 August 2011, by invitation of the Spanish Committee for Crystallography on behalf of the Subdirección General de Programas y Organismos Internacionales, Ministerio Educación y Ciencia. A report, including a detailed report of the General Assembly, has been published [Acta Cryst. (2012), A68, 607664]. The General Assembly and Congress were attended by 2655 scientists and 113 accompanying persons from 73 countries and territories. The Ninth Ewald Medal and Prize were accepted by Professor E. Dodson, Professor C. Giacovazzo and Professor G. M. Sheldrick at the Opening Ceremony. The second Gjønnes Medal in Electron Crystallography was awarded to Professor A. Howie and Professor M. Whelan. There were 4 Plenary Lectures, 36 Keynote Lectures, 98 Microsymposia and Open Commission Meetings. The abstracts in the published book of Collected Abstracts were prepared from electronic submissions and were also provided on a CD-ROM. A commercial exhibition comprising 65 companies and booksellers was organized. The General Assembly met on the evenings of Tuesday 23 August, Wednesday 24 August and Saturday 27 August. Applications for membership from Bulgaria (Category I) and the Republic of Ireland (Category I) were accepted. The change in the name of the Adhering Body for the People's Republic of China was accepted. The Minutes of the Twenty-First General Assembly in 2008 were approved. Amendments to the Statutes and By-Laws were approved. The General Assembly received the triennial financial report and the reports of the Executive Committee, the Commissions, the Scientific Associates and Regional Associates and the Union Representatives on Other Bodies since the Twenty-First General Assembly in 2008. New officers of the Union, Chairs and members of Commissions and Union Representatives were elected; the full list of these people is given as an Appendix to the report of the TwentySecond General Assembly and Congress. The formation of a new Commission on Magnetic Structures was approved. Reports of the Chair of the Sub-committee on the Union Calendar, of the Chair of the Committee for the Maintenance of the CIF Standard and of the Editors of the IUCr Newsletter were received. The good progress of the IUCr/Oxford University Press Book Series was noted. The General Assembly approved the recommendation that the unit contribution should remain unchanged at CHF 1000 for the years 2012-2014 inclusive. It reaffirmed its decision to hold the TwentyThird General Assembly and Congress in Montreal, Canada, in 2014. It also accepted an invitation from the Indian National Science Academy and the Indian Crystallographic Association to hold the Twenty-Fourth General Assembly and Congress in Hyderabad, India, in 2017. The Executive Committee met for several days before and most days during the Congress, mainly to deal with matters directly related to the business of the General Assembly and the work of the Commissions.

\section{Other meetings}

The IUCr sponsored the following meetings held during 2011:

XIII Intensive School on X-ray Structure Analysis, Durham, UK, 26 March - 3 April.

RapiData 2011, Brookhaven, USA, 3-8 April.

Improving the Data Quality and Quantity for XAFS Experiments, Tsukuba, Japan, 12-13 April [postponed until 8-9 December].

School of Fundamental Crystallography, Mahdia, Tunisia, 25-29 April [meeting postponed until 9-13 April 2012].

X-ray Techniques for Materials Research - From Laboratory Sources to Free Electron Lasers Symposium at the European Materials Research Society Spring Meeting, 9-13 May.

Workshop on Crystallographic Software, Tokyo, Japan, 22-26 May [meeting postponed until 12-16 December].

3rd International School on Biological Crystallization, Granada, Spain, 22-27 May.

SMARTER 2 Structure Elucidation by Combining Magnetic Resonance, Computation Modelling and Diffraction, Aveiro, Portugal, 23-27 May.

Annual Meeting of the American Crystallographic Association, New Orleans, USA, 28 May - 2 June.

Electron Crystallography - New Methods to Explore Structure and

Properties of the Nanoworld, Erice, Italy, 2-12 June.

The Power of Powder Diffraction, Erice, Italy, 2-12 June.

International School on Resonant Elastic X-ray Scattering in Condensed Matter (REXS 2011), Aussois, France, 13-17 June.

Zürich School of Crystallography - Bring Your Own Crystals, Zürich, Switzerland, 13-16 June.

XVII International Conference on Crystal Chemistry, X-ray Diffraction and Spectroscopy of Minerals, St Petersburg, Russia, 2024 June.

Workshop on Mathematical Crystallography, Manila, Philippines, 2-6 November.

Third School of the Argentinian Crystallography Association, Bariloche, Argentina, 7-18 November.

School of Crystallization and Crystallography for Latin America, Florianopolis, Brazil, 12-25 November.

VIII International School on Crystallography and X-ray Diffraction, Havana, Cuba, 21-25 November.

Workshop on Crystallography at the 6th International Conference of the African Materials Research Society, Victoria Falls, Zimbabwe, 11-16 December.

\section{Executive Committee}

The membership of the Executive Committee, including new members elected at the General Assembly in 2011, is as follows: President: Professor G. R. Desiraju (India); Vice-President: Professor C. Lecomte (France); General Secretary and Treasurer: Professor L. Van Meervelt (Belgium); Immediate Past President: Professor S. Larsen (Denmark); Ordinary members: Professor E. Boldyreva 
(Russia), Dr H. A. Dabkowska (Canada), Professor W. Depmeier (Germany), Professor J. M. Guss (Australia), Professor M. L. Hackert (USA), Professor J. M. Perez-Mato (Spain).

\section{Publications}

Volume 67 of Acta Crystallographica, Volume 44 of Journal of Applied Crystallography (JAC) and Volume 18 of Journal of Synchrotron Radiation (JSR) were published.

\section{Adhering Bodies}

A list of Adhering Bodies of the Union, with names and addresses of the Secretaries of the National Committees for Crystallography, was published as Appendix D to the Report of the Twenty-Second General Assembly and International Congress of Crystallography [Acta Cryst. (2012), A68, 607-664].

\section{Work of the Commissions}

\subsection{Commission on Journals}

\subsubsection{Overview}

\begin{tabular}{llllll}
\hline & 2007 & 2008 & 2009 & 2010 & 2011 \\
\hline No. of submissions & 8562 & 5765 & 7129 & 7033 & 7302 \\
$\quad$ without Acta E & 2108 & 1919 & 2016 & 1905 & 1831 \\
Rejection rate (\%) & 21 & 24 & 22 & 22 & 22 \\
No. of published papers & 6637 & 4795 & 5440 & 5431 & 5650 \\
$\quad$ without Acta E & 1456 & 1239 & 1274 & 1318 & 1206 \\
No. of open-access papers & 284 & 3647 & 4245 & 4232 & 4571 \\
$\quad$ without Acta E & 225 & 89 & 79 & 119 & 127 \\
No. of pages & 16138 & 11295 & 12812 & 13156 & 12667 \\
$\quad$ print & 6673 & 5847 & 6385 & 6277 & 5470 \\
$\quad$ online-only & 9465 & 5448 & 6427 & 6879 & 7197 \\
\hline
\end{tabular}

The total number of articles published in IUCr journals in 2011 was slightly higher than in recent years at 5650. This is primarily due to an increase in articles published in Sections $\mathrm{E}$ and F, and masks a fall in the number of articles published in more established journals. This fall was particularly pronounced for Section C. The year saw the publication of 4571 open-access articles; there are now over 18000 open-access articles available from Crystallography Journals Online.

IUCr journals were highly ranked amongst crystallographic journals, with Section A having the highest impact factor at 54.3, Section $\mathrm{D}$ having an impact factor of 6.3 and $J A C$ having an impact factor of 3.8. Sections $\mathrm{B}$ and $\mathrm{C}$, and $J A C$ had cited half-lives of $>10$ years. A total of 3190607 downloads of journal articles were made from Crystallography Journals Online in 2011. The highest number of downloads was for Section E. A small number of structures were retracted from Section $\mathrm{E}$ during the year, and investigations of further suspect structures published prior to the instigation of the new validation procedures are ongoing.

Commission on Journals meetings were held in El Escorial, Spain, just before the IUCr Congress, and were attended by over 90 editors and Chester staff. More than a full working day was available to discuss all relevant matters of scientific editing and related issues. Less time than at previous occasions was used for large plenary sessions and formal presentations. Apart from the opening and closing plenary meetings there were a number of smaller meetings that covered individual journals or groups of journals. Special sessions were also held that covered author tools, online submission, the review process, technical editing and journal production processes, all in interactive mode. Topics discussed at the meetings included refereeing standards, publication ethics and open access, as well as promotion of the journals, improvement in communications between editors, and developments in the submission and review system. Suggestions on extending the scope of Section A were considered, as was the question of how to make Section B more attractive to authors. It was also agreed that $J S R$ should be active in attracting papers on free-electron lasers. The policy of early appointments of Co-editors before the Congress meant that 17 newly appointed Co-editors were able to attend the Commission meeting. It is hoped that this policy can be continued for the Congress in Montreal in 2014.

At its meeting during the Madrid Congress, the IUCr Executive Committee set up a Journals Review Committee to consider the medium- and long-term development of the journals. The Committee is being chaired by Sven Lidin and will report in early 2012. Although the wait-and-see attitude induced by the formation of the Journals Review Committee resulted in a loss of momentum in ongoing and planned initiatives, some changes already took effect: Section A widened its scope, Section B has started to brush up its profile, Section C considered its standards and goals, and JSR added a logo alerting to the coverage of 'Free-electron lasers' to its front cover. The meetings (e-mail) circular distributed by the Promotions Officer in collaboration with the Managing Editor and the Editor-in-Chief now regularly alerts all editors and a large number of active crystallographers to relevant meetings and asks for help in promoting the journals, if they attend. The feedback is very satisfactory, but promotional efforts definitely need further, more professional enhancements.

At Chester, tools for authors and readers continued to be developed in 2011. A streamlined version of publBio, a 'cloud' application that can be used to prepare the experimental data tables, the text and the figures for biological articles, was launched. The 3D view facility in Crystallography Journals Online was upgraded to include a chemical view of structures and also improved ellipsoid representations.

A number of Special Issues were produced in 2011. Proceedings of the CCP4 Study Weekend: From Crystal to Structure with CCP4 were published in Section D. A Special Issue on The Seattle Structural Genomics Center for Infectious Disease was published in Section F. Papers presented at the 3rd International Symposium on Diffraction Structural Biology (ISDSB 2010) and the Sixth International Workshop on X-ray Radiation Damage to Biological Crystalline Samples were published in $J S R$. It may be concluded that very well focused Special Issues on topics of current interest provide a useful service to the community and may improve the visibility of the IUCr journals. A new development was the publication of a virtual Special Issue on Polymorphism in Section C; this was well received and future virtual issues are planned.

At the end of the year, more than 160 Section Editors and Coeditors worked on IUCr journals. The work of all these dedicated colleagues is highly appreciated. The year marked the retirements of a number of Editors and Co-editors: Dieter Schwarzenbach retired from Section A to be replaced by Walter Steurer; Carol Brock retired from Section B to be replaced by Sander van Smaalen; Jim Simpson retired from Section E to be replaced by Helen Stoeckli-Evans and Edward Tiekink; and Åke Kvick and Toshiaki Ohta retired as Editors of $J S R$. They all deserve our gratitude and best wishes for their future activities.

\section{G. Kostorz, Chair}




\subsubsection{Acta Crystallographica Section A}

\begin{tabular}{llllll}
\hline & 2007 & 2008 & 2009 & 2010 & 2011 \\
\hline No. of submissions & 106 & 96 & 116 & 100 & 134 \\
Rejection rate (\%) & 33 & 33 & 39 & 40 & 40 \\
No. of published papers & 66 & 81 & 56 & 81 & 68 \\
$\quad$ research papers & 46 & 42 & 41 & 66 & 56 \\
$\quad$ short communications & 3 & 6 & 5 & 3 & 5 \\
$\quad$ lead articles & 1 & 0 & 1 & 1 & 0 \\
$\quad$ feature articles & 0 & 24 & 1 & 1 & 0 \\
$\quad$ editorial & 0 & 0 & 0 & 3 & 0 \\
$\quad$ abstracts & 665 & 2059 & 735 & 734 & 2087 \\
$\quad$ other & 16 & 9 & 8 & 7 & 7 \\
No. of open-access papers & 5 & 0 & 0 & 2 & 6 \\
No. of pages & 510 & 702 & 548 & 724 & 565 \\
Average length (pages) & 9.1 & 10 & 10.3 & 9.8 & 9 \\
Average publication time (months) & 5.3 & 5.3 & 5 & 5.7 & 4.7 \\
Impact factor & 2.39 & 2.05 & 49.93 & 54.33 & \\
Cited half life (years) & $>10.0$ & $>10.0$ & $>10.0$ & 6.2 & \\
\hline
\end{tabular}

In 2011, Section A published 565 pages in six issues as well as 823 abstracts from the Madrid Congress. The number of pages and the number of published papers are within the range of the preceding four years. There are also no significant upwards or downwards trends for other parameters such as rejection rate, average length or publication time (2010 being an exception caused by a few very long reviews). The geographical distribution of the origins of the articles (by corresponding authors) was $57 \%$ from Europe, $31 \%$ from the Americas and 12\% from Asia. By 18 May 2012, 35 of these articles had already been cited 81 times ( 61 without self-citations) in total (42 citations in 2011, plus another 39 in 2012 so far). The scientific scope of Section A has been widened and the journal now welcomes articles reporting fundamental advances in all areas of crystallography in the broadest sense. This includes metacrystals such as photonic or phononic crystals, i.e. structures on the meso- or macroscale that can be studied with crystallographic methods. The central themes are, on the one hand, experimental and theoretical studies of the properties and arrangements of atoms, ions and molecules in condensed matter, periodic, quasiperiodic or amorphous, ideal or real, and, on the other, theoretical and experimental aspects of the various methods for determining these properties and arrangements. In the case of metacrystals, the focus is on the methods for their creation and on the structure-property relationships for their interaction with classical waves.Although the focus has been widened, it is still clearly on the theoretical discussion of different aspects of structure analysis with $\mathrm{X}$-rays or electrons, on methods and methodology. There have already been two papers on the evaluation of structural studies using XFELs. A few papers discuss specific or general problems of structural ordering. A similar number of articles deal with questions of mathematical crystallography.There were several cases where authors persisted with trying to get their manuscript published despite clearly negative referee reports. One author gave up after being able to submit their manuscript to arXiv.org. Another author appealed against the decision of the Section Editor; the paper was finally rejected by the Editor-in-Chief.The electronic system works well enough for all operations a submission might require, but in the course of manuscript revision authors usually prefer direct contact via e-mail.The success of Section A is due to the combined efforts of many persons. The collaboration with the Editorial Office in Chester is extremely good and always efficient, with very fast and competent answers to all questions. I thank in particular Nicola Ashcroft for her competent work and friendly communication. I also thank all the Coeditors for their often difficult work and decisions. Finally, Dieter Schwarzenbach retired as the Section Editor at the Madrid Congress and it is my pleasure to thank him for all his work for the journal over the years. Co-editors retiring in the summer included André Authier, Philip Coppens, Rick Millane, Manuel Perez-Mato, Kiyo Tanaka and Helmuth Zimmerman - they are thanked for all their contributions to the journal.

W. Steurer, Editor of Section A

6.1.3. Acta Crystallographica Section B

\begin{tabular}{llllll}
\hline & 2007 & 2008 & 2009 & 2010 & 2011 \\
\hline No. of submissions & 157 & 134 & 138 & 96 & 121 \\
Rejection rate (\%) & 41 & 35 & 34 & 40 & 40 \\
No. of published papers & 110 & 91 & 90 & 73 & 57 \\
$\quad$ research papers & 101 & 81 & 76 & 71 & 52 \\
$\quad$ short communications & 3 & 5 & 4 & 0 & 1 \\
$\quad$ feature articles & 1 & 0 & 3 & 1 & 1 \\
$\quad$ other & 5 & 5 & 7 & 1 & 3 \\
No. of open-access papers & 4 & 1 & 2 & 3 & 5 \\
No. of pages & 940 & 791 & 790 & 706 & 581 \\
Average length (pages) & 8.9 & 9.3 & 9.6 & 9.8 & 10.7 \\
Average publication time (months) & 5.8 & 5 & 4.9 & 5.2 & 4.6 \\
Impact factor & 2.16 & 2.34 & 1.8 & 1.83 & \\
Cited half life (years) & $>10.0$ & $>10.0$ & $>10.0$ & $>10.0$ & \\
\end{tabular}

The decline in the number of papers published in Section B (at stable rejection rates) continues to be of concern. The decline in the number of papers submitted in 2010 was highlighted in the last report and it is clearly reflected in the latest statistics for 2011. The total number of pages published for 2011 was 581 (down from 706 in 2010), which is the lowest seen since 1985 . The number of articles published decreased from 73 in 2010 to 57 in 2011. However, the number of submissions increased from 96 in 2010 to 121 in 2011, which is due especially to submissions in the second half of 2011. The rejection rate remains high at $40 \%$. The average length of an article has continued to rise gradually from 8.9 pages in 2007 to 10.7 pages in 2011. The impact factor remained stable around 1.8 in 2009 and 2010.

Useful discussions were held in the summer when Co-editors and Section Editors met at the Commission on Journals meetings in Madrid. Many ideas were put forward as to how to improve the number of papers submitted, including publishing more Special Issues, Feature Articles and Lead Articles. There are currently no Special Issues planned but many suggestions have been made that are being followed up. An immediate target is to publish more Feature Articles and Lead Articles on topics of high current interest. This track is followed by the Editor with high priority, and Co-editors have been encouraged actively to seek authors who may be willing to write such papers. One Feature Article was published in 2011 (Structural building principles of complex face-centered cubic intermetallics, by $\mathrm{J}$. Dshemuchadse, D. Y. Jung and W. Steurer). Ways of reducing review times have been discussed and the Chester staff are investigating how to improve this situation. Overall publication times fell to 4.6 months in 2011.

Numerous editorial changes came into effect at the Madrid Congress. Carol Brock retired as the Section Editor and it is my pleasure to thank Carol for all her hard work and support for the journal over the years. Co-editors retiring in the summer included Chick Wilson, Gervais Chapuis and Tim White - we thank them all for their contributions to the journal. After having served on the editorial board for Section B as a Co-editor for many years, I have now taken on the role of Section Editor and look forward to the challenges ahead.

S. van Smaalen, Editor of Section B 
international union of crystallography

6.1.4. Acta Crystallographica Section C

\begin{tabular}{llllll}
\hline & 2007 & 2008 & 2009 & 2010 & 2011 \\
\hline No. of submissions & 928 & 751 & 687 & 592 & 479 \\
Rejection rate (\%) & 52 & 60 & 52 & 53 & 50 \\
No. of published papers & 451 & 332 & 331 & 284 & 239 \\
$\quad$ research papers & 451 & 328 & 328 & 280 & 234 \\
$\quad$ editorial & 0 & 1 & 1 & 0 & 2 \\
$\quad$ other & 0 & 3 & 2 & 4 & 3 \\
No. of open-access papers & 19 & 2 & 1 & 1 & 0 \\
No. of pages & 1510 & 1197 & 1258 & 1134 & 993 \\
Average length (pages) & 3.4 & 3.6 & 3.8 & 4 & 4.2 \\
Average publication time (months) & 2.1 & 1.8 & 1.9 & 1.9 & 2 \\
Impact factor & 0.72 & 0.56 & 0.78 & 0.75 & \\
Cited half life (years) & $>10.0$ & $>10.0$ & $>10.0$ & $>10.0$ & \\
\hline
\end{tabular}

Acta Crystallographica Section C was pleased to be able to publish its first virtual Special Issue at the beginning of December 2011. The issue focused on polymorphism, was highlighted on the IUCr home page and has received favourable comment. We are therefore encouraged to proceed with plans for the next Special Issue to be published towards the end of 2012. The issue will focus on absolute structure, as there have been interesting developments in recent years for the measurement and evaluation of such structures. Another virtual issue being planned is a collection of structures which were quite unexpected and the origin of the compound could not readily be explained. Peter Müller will act as Guest Editor for this issue.

It is pleasing to see some papers containing an extensive discussion of the presented structures along with detailed comparisons with related structures or a discussion of the properties of the material derived from other analyses [for example, Pérez et al. (2012). Acta Cryst. C68, o19-o22; Bekouml et al. (2012). Acta Cryst. C68, o28-o32; Pourayoubi et al. (2011). Acta Cryst. C67, o265-o272]. Authors are being encouraged to submit papers of this kind.

At the same time, there is serious concern about the continuing decrease in the number of submissions to the journal, as illustrated by the above table.

We were saddened to learn of the sudden death of one of our Coeditors, Andrés Goeta, in July 2011. Andrés was not only an excellent Co-editor, but was a highly valued member of the crystallographic community at the University of Durham, UK, and in the UK in general. A most appropriate obituary written by Professor Judith Howard can be viewed at http://www.dur.ac.uk/crystallography.group/ Andres_Goeta.html. Andrés will be sadly missed by everyone.

Several Section C Co-editors retired at the Madrid Congress and it is my pleasure to record here my sincere appreciation of their sustained outstanding efforts and their support of the journal. Some of them have been active Co-editors for a long period, with the longest serving having been involved for about 17 years. The retirees are: Jean-Claude Daran, Graeme Gainsford, Christopher Glidewell, Peter Jones, Phil Squattrito, Helen Stoeckli-Evans and Karl Törnroos. Warm thanks also go out to all current Section C Co-editors and the Chester Editorial Office staff for their dedicated support and contributions to the ongoing daily operations of the journal.

\section{A. Linden, Editor of Section C}

\subsubsection{Acta Crystallographica Section D}

Biological Crystallography, Section D of Acta Crystallographica, continues to publish papers devoted to both methods of macromolecular crystallography and novel structures of biological interest. In 2011 a total of 1077 pages were published, encompassing 119 Research Papers, 5 Short Communications, and 7 other short

\begin{tabular}{llllll}
\hline & 2007 & 2008 & 2009 & 2010 & 2011 \\
\hline No. of submissions & 193 & 191 & 205 & 201 & 239 \\
Rejection rate (\%) & 23 & 19 & 19 & 22 & 26 \\
No. of published papers & 157 & 152 & 160 & 167 & 131 \\
$\quad$ research papers & 128 & 135 & 136 & 148 & 119 \\
$\quad$ short communications & 18 & 13 & 16 & 11 & 5 \\
$\quad$ feature articles & 1 & 0 & 0 & 0 & 0 \\
$\quad$ editorial & 1 & 1 & 1 & 4 & 0 \\
$\quad$ other & 9 & 3 & 7 & 4 & 7 \\
No. of open-access papers & 24 & 33 & 43 & 37 & 27 \\
No. of pages & 1283 & 1294 & 1349 & 1354 & 1077 \\
Average length (pages) & 9.1 & 9.1 & 9.1 & 8.7 & 8.8 \\
Average publication time (months) & 4.4 & 4.4 & 4.5 & 5.1 & 4 \\
Impact factor & 2.62 & 2.94 & 2.26 & 6.33 & \\
Cited half life (years) & 8.9 & 9.7 & 9.4 & 9 & \\
\hline
\end{tabular}

presentations (4 Corrigenda, a Book Review, Notes for Authors and an introduction to the CCP4 Proceedings Special Issue). Among the research papers, two-thirds (80) presented novel biological structures and one-third (39) were methodological. Despite the fact that it competes with many other journals publishing biological structures, Acta $D$ continues to attract structural papers of considerable biological interest and excellent quality. Moreover, the initiative taken by Acta $D$ and Acta $F$ to require validation reports for structural papers is now beginning to be taken up by other journals (recently J. Biol. Chem.) - an indication of our leadership in this area.In 2010 the impact factor of Acta D was 2.3, but in 2011 it increased to 6.3, comparing very favourably with many other journals publishing structural biology results. Acta $D$ is the primary venue for publication of papers describing novel ideas in methods for macromolecular crystallography, and has practically no competition in this aspect. It does face very strong competition from many biological journals, however, for publication of structural papers. It may be envisaged that the very significant increase in the impact factor of Acta D will attract an increased number of high-profile structural papers to the journal. Indeed, we already see signs of this with increased numbers of submissions. The CCP4 Special Issue in April 2011 was entitled From Crystal to Structure with CCP4 and was edited by Kevin Cowtan, Paul Emsley, Keith Wilson and Charles Ballard, who deserve special thanks for their efforts to prepare this very important issue. It presented a number of significant new additions to the wide existing spectrum of approaches available in the CCP4 suite as well as in some other programs. The papers included in this issue will most probably be very widely cited, as is usual for the traditional, annual CCP4 Study Weekend Special Issues. We wish to thank all the people who contribute to the success of Acta D, in particular our devoted Coeditors, many anonymous referees, and especially Louise Jones and Simon Glynn in Chester for their excellent work in the Editorial Office, which results in the superb quality of our journal. Finally, we would like to thank the following retiring Co-editors for all their hard work on the journals: Naomi Chayen, Steve Ealick, Mitchell Guss, Hazel Holden, Bill Hunter, Marc Pusey and Peter Timmins.

E. N. Baker and Z. Dauter, Editors of Section D

\subsubsection{Acta Crystallographica Section E}

2011 was a successful year for Acta Crystallographica Section E with 5471 articles submitted and 5523 pages published. Publication times remained low with an average submission-to-publication time of 0.7 months. Papers have been submitted from 80 countries, the five top contributors being People's Republic of China, India, Malaysia, USA and South Africa, with the greatest increase in submissions from South Africa, $c a 2.5 \%$ compared to 2010 . 


\section{international union of crystallography}

\begin{tabular}{llllll}
\hline & 2007 & 2008 & 2009 & 2010 & 2011 \\
\hline No. of submissions & 6454 & 3846 & 5113 & 5128 & 5471 \\
Rejection rate (\%) & 17 & 16 & 18 & 18 & 19 \\
No. of published papers & 5181 & 3556 & 4166 & 4113 & 4444 \\
$\quad$ research papers & 5166 & 3533 & 4151 & 4091 & 4434 \\
$\quad$ editorial & 1 & 1 & 1 & 1 & 0 \\
$\quad$ other & 14 & 22 & 14 & 21 & 10 \\
No. of open-access papers & 59 & 3558 & 4166 & 4113 & 4444 \\
No. of pages & 8375 & 4261 & 5108 & 5195 & 5523 \\
Average length (pages) & 1.6 & 1.2 & 1.2 & 1.3 & 1.2 \\
Average publication time (months) & 0.8 & 0.8 & 0.7 & 0.7 & 0.7 \\
Impact factor & 0.51 & 0.37 & 0.41 & 0.41 & \\
Cited half life (years) & 1.8 & 2.4 & 2.7 & 3.1 & \\
\hline
\end{tabular}

Developments continue to be made to the submission system and to the online content, including an improved $3 \mathrm{D}$ view page, which now shows a chemical view of structures and improved ellipsoid representations. The proofs sent to the authors have also been enhanced and now include the supplementary material as well as the short-format paper.

We continue to maintain a vigilant watch for potentially fraudulent structures. The validation procedures continue to be improved so that problems such as incorrect element assignment are more readily identified and can be challenged. Reduced-cell checking combined with checks for similar structure factors are now a routine part of the review process. However, 11 structures were retracted in March and a further five in October, and investigations of further suspect structures published prior to the instigation of the new validation procedures are ongoing.

Twenty-seven members of the Section E Editorial Board attended the Commission on Journals meetings prior to the Madrid Congress. The sessions for Acta E Co-editors concentrated on problems commonly encountered in submissions and highlighted the changes that need to be made at the review stage to make an article suitable for publication. The discussion of the specific requirements for metalorganic structures included tips for spotting element swapping. There was also a presentation on the measures put in place to detect fraud, tips on identifying problem structures and details of how possible cases are investigated.

Jim Simpson stepped down as a Section Editor of Section E at the Madrid Congress to be replaced by Helen Stoeckli-Evans and Edward Tiekink. Jim has made a tremendous contribution to the journal and his leadership has been invaluable, not least during the fraud investigations. He will continue to work for the journal as a Coeditor. A number of Co-editors retired at the Congress and others during the year, and it is our pleasure to record here our sincere appreciation of their sustained outstanding efforts and their support of the journal. The retirees are: Kumar Biradha, Kandasamy Chinnakali, Jean-Claude Daran, Judy Flippen-Anderson, Ken Haller, Owen Johnson, John Low, Arthur Mar, Marilyn Olmstead, Damon Parrish, Helmut Schmalle, Wing-Tak Wong and Alex Yanovsky. Warm thanks also go out to all current Section E Co-editors and the Chester Editorial Office staff for their dedicated support and contributions to the ongoing daily operations of the journal.

W. T. A. Harrison, H. Stoeckli-Evans, E. R. T. Tiekink and M. Weil, Editors of Section $\mathrm{E}$

\subsubsection{Acta Crystallographica Section F}

In 2011, its seventh year of publication, Section F published 365 original science articles in 1674 pages. Importantly, as for 2010, 99 of those articles, more than a quarter, were structure or laboratory

\begin{tabular}{llllll}
\hline & 2007 & 2008 & 2009 & 2010 & 2011 \\
\hline No. of submissions & 317 & 349 & 422 & 421 & 401 \\
Rejection rate (\%) & 10 & 10 & 9 & 9 & 8 \\
No. of published papers & 282 & 302 & 333 & 377 & 385 \\
$\quad$ research papers & 279 & 293 & 328 & 362 & 365 \\
$\quad$ editorial & 0 & 5 & 2 & 4 & 3 \\
$\quad$ other & 3 & 4 & 3 & 11 & 17 \\
No. of open-access papers & 13 & 8 & 11 & 41 & 41 \\
No. of pages & 1090 & 1187 & 1319 & 1684 & 1674 \\
Average length (pages) & 3.9 & 4 & 4 & 4.5 & 4.4 \\
Average publication time (months) & 2.4 & 2.6 & 2.8 & 3.6 & 3.9 \\
Impact factor & 0.65 & 0.61 & 0.55 & 0.56 & \\
Cited half life (years) & & 2.3 & 2.7 & 2.7 &
\end{tabular}

communications. The average time from submission to publication, however, rose from 3.6 to 3.9 months, a further drift upward. Since rapid publication has been a mandate of our journal since its inception, this issue is of course of some concern. Efforts to investigate the source(s) of this drift and to develop measures to bring publication times down again are ongoing.

The special referee panel continued to perform well in 2011. Five new members were added to replace three who resigned and two who were promoted to the position of Co-editor. We continue to believe that this panel is needed to drive down publication times while maintaining high standards of quality. The list of the inaugural panel members was published in an editorial in the November 2011 issue.

The September 2011 issue was the second full issue devoted to the work of a structural genomics group, in this case The Seattle Structural Genomics Center for Infectious Disease. This issue contains an overview article, eight laboratory communications and 21 structure communications, three of which are solution structures determined by NMR. We had hoped to see further demand for special sections and issues from structural genomics and other groups, but have not had any new inquiries so far. The Special Issues are the primary contributor to the striking increase in the percentage of structure and laboratory communications in the last couple of years and we welcome this significant shift in the balance of papers we publish.

Finally, our impact factor for 2010 increased to 0.56 , reversing the trend downward from the low value of 0.55 for 2009 . We have reason to hope that the papers attracted by the Special Issues will continue the rise in this widely consulted number.

H. M. Einspahr and M. Weiss, Editors of Section F

6.1.8. Journal of Applied Crystallography

\begin{tabular}{llllll}
\hline & 2007 & 2008 & 2009 & 2010 & 2011 \\
\hline No. of submissions & 258 & 258 & 282 & 309 & 266 \\
Rejection rate (\%) & 23 & 39 & 34 & 32 & 34 \\
No. of published papers & 314 & 161 & 172 & 222 & 180 \\
$\quad$ research papers & 118 & 117 & 126 & 165 & 131 \\
$\quad$ short communications & 152 & 9 & 9 & 11 & 8 \\
$\quad$ lead articles & 0 & 1 & 0 & 0 & 0 \\
$\quad$ editorial & 2 & 0 & 0 & 2 & 0 \\
$\quad$ other & 42 & 34 & 37 & 44 & 41 \\
No. of open-access papers & 151 & 10 & 11 & 10 & 6 \\
No. of pages & 1895 & 1197 & 1212 & 1543 & 1306 \\
Average length (pages) & 8.1 & 8.5 & 7.9 & 8.0 & 8.1 \\
Average publication time (months) & 6.3 & 5.8 & 5.4 & 5.7 & 5.1 \\
Impact factor & 3.63 & 3.21 & 3.02 & 3.79 & \\
Cited half life (years) & $>10.0$ & $>10.0$ & $>10.0$ & $>10.0$ & \\
\hline
\end{tabular}

$J A C$ continues to publish articles on a diverse range of topics, with many of the articles being of general interest to the crystallographic community. The impact factor of the journal remained high at 3.8, and 
submissions to the journal were again high with 266 articles submitted.

The JAC Board met just before the Madrid Congress and discussed a number of topics including development of the journal, Special Issues and policy matters. With regard to Special Issues, the publication of a number of Special Issues has been under consideration, and work was started in 2011 towards the publication (in 2012 or 2013) of a Special Issue on diffraction imaging techniques. An issue providing selected papers from the 11th Biennial Conference on High Resolution X-ray Diffraction and Imaging (XTOP 2012) is also planned.

Online submission is now used exclusively and works well. Publication times have gradually reduced over the last five years, and efforts to improve the review system are being made to ensure that this trend continues.

A number of $J A C$ Co-editors retired at the Madrid Congress and it is my pleasure to thank them for all their hard work over the years for the journal. The retirees are: Daniel Chateigner, Eleanor Dodson, Steve Ealick, Jean-Louis Hodeau, Ken-ichi Ohshima and Richard Welberry. My thanks also go out to all current $J A C$ Co-editors for their dedicated work in overseeing the peer-review process and the Editorial Office staff in Chester for an excellent job in preparing articles for publication.

\section{A. Kaysser-Pyzalla, Editor of JAC}

\subsubsection{Journal of Synchrotron Radiation}

\begin{tabular}{llllll}
\hline & 2007 & 2008 & 2009 & 2010 & 2011 \\
\hline No. of submissions & 149 & 140 & 166 & 186 & 191 \\
Rejection rate (\%) & 22 & 31 & 21 & 27 & 28 \\
No. of published papers & 76 & 120 & 132 & 114 & 146 \\
$\quad$ research papers & 64 & 73 & 109 & 96 & 123 \\
$\quad$ short communications & 1 & 37 & 8 & 5 & 8 \\
$\quad$ feature articles & 1 & 0 & 0 & 2 & 0 \\
$\quad$ editorial & 0 & 0 & 0 & 0 & 2 \\
$\quad$ other & 10 & 10 & 15 & 11 & 13 \\
No. of open-access papers & 9 & 35 & 11 & 25 & 42 \\
No. of pages & 535 & 666 & 883 & 816 & 948 \\
Average length (pages) & 7.8 & 5.8 & 7.5 & 7.7 & 7 \\
Average publication time (months) & 5 & 6.4 & 5.3 & 5.2 & 5.4 \\
Impact factor & 2.98 & 2.33 & 1.99 & 2.34 & \\
Cited half life (years) & 6.1 & 6.2 & 6.1 & 6.4 & \\
\hline
\end{tabular}

$J S R$ continues to provide the synchrotron-radiation research community with a place for publication of important research and instrumentation/technique development.

2011 saw the first of a new category of paper published in JSR: beamline papers, which are short descriptive papers providing details of beamlines available to users at synchrotron facilities around the world. From the number of submissions received so far, early signs are good and we expect this will be a popular category of paper of interest to the synchrotron community.

$J S R$ has continued to publish its Facility Information pages. Synchrotron facilities are invited to publish one page per issue to communicate news and updates to the international community of synchrotron-radiation users. In return, the facilities are offered a number of papers per year as open access for affiliated authors.

The advent of the new free-electron laser facilities being built around the world has highlighted the growth of interest and expectations in this area. $J S R$ has reflected the importance of this field by including a free-electron laser logo on the journal front cover; this has also been highlighted in the online pages.
Two Special Issues of $J S R$ were published in 2011. These included papers from the 3rd International Symposium on Diffraction Structural Biology (ISDSB 2010) and from the Sixth International Workshop on X-ray Radiation Damage to Biological Crystalline Samples. Two more Special Issues are planned for 2012, which will comprise selected papers from the International Workshop on Improving Data Quality and Quantity for XAFS Experiments (Q2XAFS2011) and from the Seventh International Workshop on X-ray Radiation Damage to Biological Crystalline Samples.

The following Co-editors retired at the Madrid Congress, and we would like to thank them all for their work on the journal: Lonny Berman, Heinz Graafsma, Hideo Kitamura, Åke Kvick and Toshiaki Ohta. The latter two were Main Editors of the journal, such that for the first time since its launch in $1994 J S R$ has now just one Main Editor.

\section{G. Ice, Editor of $J S R$}

\subsection{Commission on International Tables}

The series International Tables for Crystallography consists of eight volumes (A-G and A1) plus the Brief Teaching Edition of Volume A. A new edition of Volume F (Crystallography of Biological Macromolecules) was completed in 2011; new editions of Volumes A1 and E appeared in 2010. A new edition of Volume A is being finalized. Revisions of Volumes B and C are being organized. A ninth volume (Volume H, Powder Diffraction) is in preparation. Discussions of new volumes covering magnetic space groups and EXAFS/XRF have been initiated.

An important development is the expanded content available to online subscribers only. The Symmetry Database server associated with Volume A (see below) represents a major step in this direction. It seems likely that the electronic content of new and revised volumes will increase.

Sales of the individual volumes and of access to the online volumes remain strong.

Reports for the individual volumes follow.

6.2.1. Volume A (Space-Group Symmetry; Editor M. Aroyo) (including the Brief Teaching Edition and the Symmetry Database server). The work on the forthcoming sixth edition of Volume A is nearing completion. It is expected that typesetting will begin in mid2012 and that publication will take place in 2013. The most important developments are summarized as follows:

(i) Part 3 (Advanced Topics in Crystallography) consists of six chapters, including an article on magnetic subperiodic groups and magnetic space groups. Most of the text material of Part 3 is in its final form. The new and substantially modified articles have been sent for peer-reviewing.

(ii) Owing to the reduction of the tabulated data (no maximalsubgroup and minimal-supergroup data, which are now in Volume A1) the tables of plane and space groups included in Part 2 of the sixth edition will be about 100 pages shorter than those in the fifth edition. The guides to the use of the tables are at an advanced stage.

(iii) There has been some delay in the preparation of the material for the introductory Part 1 of the sixth edition. Peer-reviewing of the texts of Part 1 is estimated to take place during the second half of 2012.

Brief Teaching Edition. The plans for the Brief Teaching Edition are strongly related to the preparation of the sixth edition of Volume A. The first part of the Brief Teaching Edition will be an extended version of the introductory part of the sixth edition of Volume A, 
including additional illustrative examples and exercises to provide the reader with practical experience in the use of the crystallographic symmetry data. The second part of the Teaching Edition will focus on the presentation of the tabulated symmetry data of Volume A, including descriptions of the symbols and terms applied in the tables and detailed guides for their use.

Owing to the delay in the preparation of the material for the introductory part of Volume A, the initial versions of the texts for Part 1 of the Brief Teaching Edition are expected only at the end of 2012. The material for Part 2 (selection of space-group tables of Part 2 of Volume A and the corresponding symbols descriptions and guides) will also be ready by the end of 2012 .

Symmetry Database server of the online edition of International Tables. In 2011 there were certain important achievements in the enhancement of the online edition of International Tables for Crystallography. The initial stage of the project was completed and its main result is the development and launch of the Symmetry Database web server. It provides more extensive symmetry information than can be found in the print editions of Volume A and Volume A1. For example, the Symmetry Database server provides data on the generators, general positions and Wyckoff positions of all 230 space groups, including the 530 settings for the monoclinic and orthorhombic space groups. The series of isomorphic subgroups are available in a parametric form for indices up to 50 for orthorhombic, tetragonal, trigonal and hexagonal space groups and for indices up to 27 and 125 for cubic space groups. There are computer tools for the study of group-subgroup and group-supergroup relationships: e.g., transformation of a group to subgroup basis; development of procedures for left- and right-coset decomposition of a group with respect to a subgroup; and Wyckoff-position splittings for a groupmaximal subgroup pair.

Previously announced difficulties with the speed of the online programs for coset decomposition and Wyckoff-position splittings for isomorphic subgroups of relatively high indices have been overcome; the server provides online calculations for isomorphic subgroups of indices higher than 50 .

6.2.2. Volume A1 (Symmetry Relations Between Space Groups; Editor U. Müller). The most recent edition of Volume A1 (the second) was published in 2010. It consists of three parts.

Part 1 deals with group-theoretical aspects of space groups, groupsubgroup relations and the underlying mathematical background. There is a chapter giving instructions on how to relate crystal structures by group-subgroup relations and how to construct trees of group-subgroup relations for crystal structures that can be derived from a high-symmetrical structure type (aristotype). A chapter deals with the publicly accessible Bilbao Crystallographic Server with descriptions of those databases and computer programs that are related to the subjects of this volume.

Part 2 contains the complete listings of the maximal subgroups for each plane group and space group, including their general positions or their generators, their conjugacy relations and the transformations to the conventional settings. In addition, the minimal supergroups are listed.

Part 3 lists the relations between the Wyckoff positions for every maximal subgroup of every space group including the cell transformations and coordinate transformations.

In both Parts 2 and 3, the infinitely many maximal isomorphic subgroups are included in a parametrized form.

6.2.3. Volume B (Reciprocal Space). During late 2011, G. Chapuis agreed to become the Editor of Volume B; he was formally appointed in early 2012. The previous Editor had retired after the publication in 2008 of the 3rd edition. It is expected that the Editors of Volumes B and $\mathrm{C}$ will cooperate because some of the material currently in Volume $\mathrm{C}$ (e.g., the section on space groups for incommensurate structures) might be more appropriate for Volume B.

6.2.4. Volume C (Mathematical, Physical and Chemical Tables; Editor T. R. Welberry). The needed revision of Volume $\mathrm{C}$ is underway but presents considerable challenges.

The current Volume C, running to about 1000 pages, has developed over the course of a number of editions since the work on it first began in 1983. After a long lead period the first edition was published in 1992 and contained mainly new material, but with some material derived from a condensation of the original Volumes II, III and IV of International Tables for X-ray Crystallography.

When the current Editor took over, some work on revising and updating the current articles had been initiated and indeed some revisions had already been received. Scrutiny of a number of these revisions showed that the articles had been brought up to date by adding references to more recent work, but by and large the substantive content dates back to the original article and the revisions are relatively minor changes.

The articles in the current volume are quite diverse, not only in their subject matter, but in their length and depth of treatment. Some subject areas are quite mature with very little in the way of new developments, though they are still very relevant and valuable. Others are quite obsolete and, though they may have historical or even pedagogical significance, their inclusion in a new Volume $\mathrm{C}$ cannot be justified. There is also a substantial body of material that is likely to be taken over by the new Volume $\mathrm{H}$ on powder diffraction, although some of this material may have wider applicability and may also have a place in Volume C.

The main emphasis of the current effort in developing a plan for the new Volume $\mathrm{C}$ is to try to identify all new areas of crystallography (e.g., those that have developed or come to the fore over the last five to ten years) that are inadequately covered or not covered at all in the present volume.

Since the previous version of Volume $\mathrm{C}$ is now available online [first electronic edition (2006), which is very similar to the third printed edition (2004)] none of this material will be lost and will continue to be an invaluable resource into the future.

6.2.5. Volume D (Physical Properties of Crystals; Editor A. Authier). There is no plan at present for a new edition of Volume $\mathrm{D}$, which was published in 2003. The potential usefulness of a new edition is being considered.

6.2.6. Volume E (Subperiodic Groups; Editors V. Kopský and D. B. Litvin). There were no new developments during 2011.

6.2.7. Volume F (Crystallography of Biological Macromolecules; Editors E. Arnold, D. M. Himmel and M. G. Rossmann). The second edition of Volume $\mathrm{F}$ was completed and submitted to the publisher in mid-December 2011. For clerical reasons, the official publication date with the publisher is January 2012, although it is listed as 2011 on the printed copy of the volume.

The second edition drops five articles that appeared in the first volume, updates 26 articles, and adds 19 new articles covering a range of topics in macromolecular crystallography and allied fields such as electron microscopy. The new articles include such topics as standard definitions for macromolecular crystallographic statistical indicators, expression of membrane proteins, protein engineering, radiation damage, detection of merohedral twinning, determining structures in the presence of merohedral twinning, low-resolution $a b$ initio phasing, robotic crystal loading, whole-cell X-ray diffraction imaging and halogen interactions in biological crystal structures. The second edition also presents articles on software in current use by macromolecular crystallographers and structural biologists, including soft- 
ware for electron microscopy. The aim of the second edition is to maintain an up-to-date reference for structural biology, to provide standards for the quality indicator metrics of X-ray structure refinement as well as atomic model validation, and to bring to the crystallographer an overview of methods for low- and high-resolution structure determination used both in crystallography and electron microscopy.

The volume is now also available online. As of 30 March 2012, a total of 135 print copies of the new edition of Volume $F$ had been sold, according to the publisher.

6.2.8. Volume G (Definition and Exchange of Crystallographic Data; Editors S. R. Hall and B. McMahon). The Editors continue to monitor, and participate in, developments in the CIF infrastructure. Those developments have not yet reached a sufficiently mature stage for incorporation in a new edition of Volume G.

6.2.9. Volume H (Powder Diffraction; Editors C. J. Gilmore, J. A. Kaduk and H. Schenk). Volume $\mathrm{H}$ is to be a new volume devoted to powder diffraction. This is a subject of great industrial and academic importance that hitherto has only been discussed in International Tables in a fragmented way.

During the spring of 2011 an outline of the volume was discussed by members of the powder-diffraction community and amended accordingly. Since then, a web-based consultation step has been undertaken, leading to a final list of the parts and chapters. Suggestions for authors have come from members and past members of the Commission on International Tables, the Executive Committee, other IUCr officials and many individuals. The final selection of authors to be invited was made in consultation with the chair of the Commission on Powder Diffraction.

Work is proceeding well on the volume. Some statistics give the scale of this volume:

Three sections on (1) Instruments and Methods; (2) Defects, Texture, Microstructure and Fibres; (3) Applications.

There will be 63 chapters with over 80 authors and co-authors and 690 pages.

All the authors have been appointed. This was, in general, surprisingly easy, such is the reputation of International Tables. There is a wiki for authors containing chapter summaries, preferred notation, reference layouts, notes for authors, an example chapter and a transfer of copyright form.

Although the chapters are invited, they will be subject to normal refereeing procedures to ensure scientific quality and readability for the broad target audience. Therefore, referees will represent not only the specialized area of the author but also the broader community, to emphasize that both aspects are important for Volume $\mathrm{H}$.

The manuscript deadline was the end of March 2012 and manuscripts are beginning to appear, but it is clear that there will be some delays. The Editors still hope, however, for a 2013 publication date.

Further information about the volumes can be found at the home page of the Commission: http://www.iucr.org/resources/commissions/ international-tables.

\section{P. Brock, Chair}

\subsection{Commission on Aperiodic Crystals}

2011 was a particularly exciting year for the Commission (CAC) with the award of the Nobel Prize in Chemistry to our colleague Dan Shechtman. This Prize, awarded almost 30 years after the discovery of quasicrystals, served to invigorate the whole community, and helped to introduce the notion of aperiodic crystals to the greater scientific community as well as to the general public. The Prize inspired the organization of special meetings and sessions throughout the coming year, as well as the publication of special journal issues. One of these special issues, quickly published in December 2011 by the Israel Journal of Chemistry, was edited by Patricia Thiel and contains a highly recommended collection of articles by leading members of our community.

As always, in 2011 the Commission continued actively to promote aperiodic crystallography, in organizing, supporting and promoting meetings, workshops and educational activities worldwide. In doing so, the Commission continued its ongoing coordination of interaction between the various sub-communities and disciplines involved in the different aspects of research in aperiodic crystals.

The central activity for the Commission in 2011 was its active participation and promotion of aperiodic crystals at the Madrid Congress. This included three very successful Keynote Lectures and six Microsymposia related to aperiodic crystals, which the Commission helped organize. The CAC would like to acknowledge fruitful collaboration with other Commissions - the Commissions on Crystallographic Computing, Electron Crystallography, Inorganic and Mineral Structures, Mathematical and Theoretical Crystallography, Neutron Scattering, Powder Diffraction, and Synchrotron Radiation - and is looking forward to enhancing this synergetic activity in the coming years. The two-day satellite meeting Aperiodic Crystals for Beginners was organized after the conference, in Alcala de Henares, by M. de Boissieu, J. M. Perez-Mato, and M. Elena González Mosquera, and was aimed at providing an easy introduction to aperiodic crystals for beginners.

In addition to the above, two special International Symposia on Quasicrystals were held in 2011 to honor Dan Shechtman on his 70th birthday. The first was organized by the Technion in Haifa, Israel, 1213 January 2011, and the second was organized by Iowa State University in Ames, Iowa, USA, 29 July 2011. Educational activity continued strongly in 2011: the 7th Workshop on Structural Analysis of Aperiodic Crystals took place at the University of Bayreuth, Germany, 17-20 March 2011, organized by S. van Smaalen and A. Schönleber. The series of ad hoc workshops on JANA2006 continued with a record of six workshops organized by M. Dusek in Prague, Czech Republic, in January, February, March, June, July and December.

The most important upcoming meeting for the Commission is Aperiodic 2012 (http://rsc.anu.edu.au/Aperiodic2012/), to be held in Cairns, Australia, 2-7 September 2012. The meeting is organized by R. Withers, with the Commission acting as its Scientific Programme Committee. Other upcoming activities in 2012 include the 27th European Crystallographic Meeting (ECM-27), Bergen, Norway, 611 August 2012 (which will include a number of talks related to aperiodic crystals and a special symposium on quasicrystals), and Quasicrystals@TaipeiTech, an international conference celebrating the 30th anniversary of the discovery of quasicrystals, Taipei, 7-9 May 2012.

In 2011 the CAC initiated a process of coordinating and integrating its web site on the IUCr server (http://www.iucr.org/iucr/ commissions/aperiodic-crystals) with the highly popular and active web site dedicated to all aspects of the crystallography of aperiodic crystals (http://www-xray.fzu.cz/sgip/aphome.html). The latter is maintained by M. Dusek, a new consultant on the Commission, for the Special Interest Group (SIG) on aperiodic crystals of the European Crystallographic Association. We hope to complete the integration of the web sites in 2012.

The new membership of the Commission for the present triennium was approved by the General Assembly and the Commission wishes to thank its outgoing Chair, M. de Boissieu, for his many years of 
service for the promotion of aperiodic crystals, and especially for his dedicated and exceptional work as Commission Chair. During his tenure as Chair the activities of the Commission were greatly expanded and enhanced, both within the IUCr and beyond. We look forward to his continuing assistance as a consultant for years to come. The Commission also thanks those members who retired in 2011 for their commitment and service - M. Baake, K. D. M. Harris, V. Petricek, K. Saitoh, Y. Michiue, N. Speziali and P. Zavalij.

\section{R. Lifshitz, Chair}

\subsection{Commission on Biological Macromolecules}

In 2010 and 2011, a central activity of the Commission was to contribute to the design of the programme for the Madrid Congress and the invitation of speakers, including the 2009 Nobel Laureates in Chemistry. The three macromolecular crystallographers who received the Nobel Prize for determination of the ribosome structure (V. Ramakrishnan, T. A. Steitz, A. Yonath) gave individual Plenary Lectures at the Congress with full attendance, which were the highlights of this IUCr Congress and General Assembly. During the Madrid Congress, the Commission organized an Open Commission Meeting, and discussed issues such as: developing next-generation guidelines for crystallographic PDB depositions and data access (this effort will be led by T. C. Terwilliger); preparation for the IYCr (2014) celebration and for the Montreal Congress in 2014; crystallographic education, popular science etc. Also discussed were possible future publishing policies, concerning: (1) immediate release of the PDB coordinates upon publication and (2) inclusion of PDB validation reports with manuscript submission. The consensus was that these policies, if implemented, should be applied to all journals publishing in structural biology.

In the coming years, the Commission will follow and extend the IUCr's general objectives 'to promote international cooperation in crystallography and to contribute to all aspects of crystallography, to promote international publication of crystallographic research, to facilitate standardization of methods, units, nomenclatures and symbols, and to form a focus for the relations of crystallography to other sciences'. We will continue our efforts to support the vitality of the biological crystallography community, particularly through recommending and supporting IUCr proposals to hold meetings, workshops and schools. We have recommended and supported more than ten meetings via the Sub-committee on the Union Calendar since August 2011, and future meetings will be held in Asia, Africa, North and South America, and Europe, mostly in 2012 and 2013.

In 2011, Commission member T. C. Terwilliger (USA) was appointed as a member of the Diffraction Data Deposition Working Group (DDDWG), and will work as liaison between the Commission and the databases in an effort to promote communication between the IUCr and the globally critical resources such as the Protein Data Bank that store and provide convenient access to biological structural data. Dr Terwilliger proposed that the Commission focuses on nextgeneration deposition expectations for the PDB and provided a highlevel vision of key concepts for this discussion. The Commission membership enthusiastically supported Dr Terwilliger's ideas and has chosen this as one of the top focuses for our Commission's future work. The Commission has appointed Dr Terwilliger as the leader of this effort within the Commission.

The ideas Dr Terwilliger has proposed and that the Commisison members found important and exciting are complementary to, and support, the vision that the DDDWG has developed. Dr Terwilliger's key ideas are that (1) the crystallographic data are unchanging after collection, but the interpretation of those data can change over time; (2) original and subsequent interpretations of the data should be recorded and be accessible; and (3) not only the final structure, but also the process used to determine that structure are critical for evaluating the quality of the structural results, so that this process and all information needed for a complete re-determination of a structure should be recorded.

\section{Xiao-Dong Su, Chair}

\subsection{Commission on Charge, Spin and Momentum Densities}

The Commission has been active in the pre-organization of the Madrid Congress through its representative member on the International Programme Committee, K. Hämäläinen.

A Keynote Lecture was given by B. Iversen (Aarhus, Denmark), member of the Commission (2005-2011), where he reported on recent advances in charge-density studies for materials sciences, illustrating the potential of the International Center for Material Crystallography created in 2010 as a unique platform combining synthesis, charge-density characterization and theoretical modelling.

The Commission organized five scientific Microsymposia among which four were devoted to charge density: Descriptors of Electronic Structure and Chemical Bonding (MS34), Advanced Approaches in Charge Density Analysis and Derived Properties (MS41), Density Functional Methods for Electronic Structure Calculations (MS76), Hydrogen Bonding: From the Solid State to Solution (MS90). One Microsymposium was on Electron Momentum and Spin Densities in Correlated Electron Systems (MS48). Most of the sessions received a large audience and gave rise to animated discussions.

Two Microsymposia were co-proposed jointly with other Commissions (Aperiodic Crystals, Neutron Scattering and Synchrotron Radiation) on Atomic Dynamics (MS55) and Magnetism (MS96) using X-rays and neutrons.

The Open Commission Meeting was quite successful, as it attracted people from various Commissions of the IUCr. During this meeting, the next Sagamore Conference on Charge, Spin and Momentum Densities, to be held in Hokkaido, Japan, in July 2012, was presented by M. Takata. D. Jayatilaka reported on the final results of the Commission Project entitled Constrained Experimental Wavefunction, which has involved seven groups since 2005 to probe the possibilities of the TONTO program for analyzing charge-density quality X-ray diffraction data (report to be published in Acta Cryst. in 2012).

The second important event in 2011 was the International School on Charge Density organized in Jaca, Spain, as a satellite meeting of the Madrid Congress, by C. Lecomte, former Chair of the Commission (2002-2005) and F. Lahoz, current Chair of the Commission on Structural Chemistry. This school covered all aspects, both in theory and in practice, of the methods for charge-density determination through accurate high-order X-ray diffraction experiments, from data-collection procedures to the analysis of derived properties. Extensive software training was provided. The school gathered 15 tutors, internationally recognized specialists in the field and main software authors, and more than 50 attendees.

A Commission web site was created in 2011 by C. Gatti (former Chair) and is maintained by the Chair at the IUCr site http:// www.iucr.org/iucr/commissions/charge-spin-momentum-densities.

\section{B. Gillon, Chair}




\subsection{Commission on Crystal Growth and Characterization of} Materials

During 2011, the Commission was chaired by H. A. Dabkowska until August, then by A. Zappettini, who was previously a Commission member. Dr Dabkowska is still giving her incomparable contribution to the Commission, serving as a member.

Following the Madrid Congress, Sonia Baldochi (Brazil) became a member and three new consultants, T. Kuech (USA), J. Newman (Australia) and D. H. Yoon (South Korea), joined the Commission. I would like to take this opportunity to welcome the newcomers to our group and to thank D. Bliss for his strong input to the work of this Commission during his terms.

In 2011 the members of the Commission collaborated actively but mostly via the internet. However, in August, at the Madrid Congress, there was an official Open Meeting of the Commission and most of us had the opportunity to meet in person and exchange opinions about the future of crystal growth around the world. Many of the members/ consultants of the Commission were present, namely: H. A. Dabkowska, A. Moreno, J. M. Garcia-Ruiz, J. Wang, A. Zappettini, J. Newman, A. Glikin and E. Talik. Other colleagues interested in the work of the Commission were also present, among them R. Fornari, President of the International Organization for Crystal Growth (IOCG), S. Cuffini, S. Bocharov and O. Cambon.

The meeting was initially chaired by Dr Dabkowska who described briefly the work of the Commission during recent years. She also reported on her recent meeting with the IUCr Executive Committee. She then announced that A. Zappettini was nominated as the next Chair of the Commission, to be confirmed by the General Assembly.

The first topic for discussion concerned possible actions for the International Year of Crystallography. In particular, it seemed important to promote the visibility of advanced crystals together with a stronger effort to spread programmes and concepts related to crystal growth. It was suggested that an advisory board should be created to select the best pictures and the necessary teaching elements.

In 2013 the IOCG Conference will be held in Warsaw, Poland. Therefore the possibility of suggesting some topics particularly relevant to crystallography was discussed. The suggestion was supported by E. Talik, member of the Conference Advisory Committee, and R. Fornari, the Conference Chair.

It was underlined that an important point for the Commission is the organization of crystal-growth schools and conferences and the importance of improving the coordination of these efforts was mentioned. It was also suggested that the opportunity to organize a school in Africa with the support of the IUCr should be evaluated.

At the Madrid Congress the Commission was represented by J. M. Garcia-Ruiz (as a Member of the International Programme Committee). Five Microsymposia suggested by the Commission and related to crystal-growth topics (the highest number ever) were granted: (1) Wide Band Semiconductor and Other Crystals Used in Optoelectronics (organizers E. Talik and E. Calleja); (2) Crystal Growth and Interface Phenomena at the Nanoscale (organizers K. Tsukamoto and J. de Yoero); (3) The Growth and Morphology of Crystals (organizers A. Glikin and S. Lopez-Andres); (4) Biomineralization and Biomimetic Materials (organizers G. Fallini and J. Gomez-Morales); (5) High-Throughput Crystallization and Polymorphic Search in Pharmaceuticals (organizers U. Griesser and S. Reutzel-Edens).

All the Microsymposia were an excellent success as demonstrated by the large number of submitted abstracts and the number of researchers present at the oral sessions.
At the Madrid Congress Dr Dabkowska was elected as member of the IUCr Executive Committee. All of us wish to thank Dr Dabkowska for her incomparable work as Chair of this Commission and wish her the best for her new role.

In 2011 the IUCr supported the following meetings that were important for the crystal-growth community:

The Latin-American School of Crystallization and Crystallography, Florianopolis, Brazil, 13-25 November 2011.

3rd International School on Biological Crystallization, Granada, Spain, 22-25 May 2011.

In 2011 the CCGCM received requests for letters of support for several local and international crystal-growth meetings in 2012. Two important schools in 2012 have already received the support of the IUCr:

3rd International School of Crystallization, Granada, Spain, 21-25 May 2012.

International Summer School on Crystal Growth and Photovoltaic Materials, Brasov, Romania, 27 August - 1 September 2012.

As in previous years many Commission members and consultants (H. A. Dabkowska, T. Duffar, J. M. Garcia-Ruiz, K. Kakimoto, E. Vlieg and J. Wang) were involved in the work of the International Organization for Crystal Growth.

Finally, I wish to express my great honour and pleasure to serve as Chair of this Commission. I hope to give my own contribution to all the work done up to now by the Commission to bring more understanding of the role of crystals and their influence on many aspects of life and technology.

\section{A. Zappettini, Chair}

\subsection{Commission on Crystallographic Computing}

In keeping with a long tradition of such schools, the Commission organized a Computing School in Oviedo, Spain, one week before the Madrid Congress. (The school is known as the Mieres 2011 Crystallographic Computing School because the meeting site was moved to Oviedo only a few months before the event owing to logistic issues.) The school had 53 participants, including the 17 invited speakers. The school placed a strong weight on fostering one-on-one interactions, in particular through 24 hours of interactive tutorials run in parallel in up to four rooms.

The new membership of the Commission was approved by the General Assembly and the full roster of members and consultants is posted on the Commission web site on the IUCr server (http://www.iucr.org/resources/commissions/crystallographic-computing/ members).

The Commission has been discussing possible sites for the 2014 Computing School. Tentatively, it was decided to hold the meeting a week before the Montreal Congress, at Carleton University in Ottawa, Canada. P. Mercier (National Research Council) has volunteered to be the local organizer.

\section{R. W. Grosse-Kunstleve, Chair}

\subsection{Commission on Crystallographic Nomenclature}

The Commission held a closed meeting on 27 August 2011 during the Madrid Congress.

Online Dictionary of Crystallography. Editing a current definition in the Online Dictionary is by limited access only. For that reason, an IUCr discussion forum has been created which allows members of the community at large to comment on current definitions or propose new ones (Crystallography Definitions). 
The Online Dictionary may be consulted at http://reference.iucr. org/dictionary/Main_Page.

Discussion forum. A forum has been created for discussion of nomenclature issues by members of the Commission, with A. M. Glazer as moderator (Crystallographic Nomenclature).

Addition of Seitz notation for symmetry operations to the symmetry operations subtables of Volume A of International Tables for Crystallography. Two proposals have been submitted for inclusion of Seitz symbols in International Tables, one by D. B. Litvin and V. Kopský, the other by A. M. Glazer, differing in the symbols used. The Commission has decided that the Seitz symbols should not be included in the printed version of the Tables, but may be included in the online version. The Commission is being polled as to which set of symbols to include, or both, or none, in the online version.

\section{A. Authier, Chair}

\subsection{Commission on Crystallographic Teaching}

During 2011 the Commission continued to support many educational events: in addition to a series of well established schools, and following the idea of the importance of improving the teaching of the fundamentals of crystallography in countries where this discipline is not often easily accessible, the Commission also supported schools at a basic level in Tunisia (School of Crystallography, Mahdia, Tunisia, April 2011) and in Zimbabwe (Workshop on Crystallography at the 6th International Conference of the Africa Materials Research Society, Victoria Falls, Zimbabwe, December 2011). Also supported was the school From Genes to Atomic Structures: an Introduction to Synchrotron-Based Structural Biology (International Center for Theoretical Physics, Trieste, Italy, 23-27 April 2012); the school is mainly aimed at an audience of young researchers coming from northern African and eastern Mediterranean countries, where the structural biology field is now emerging and where young students need to be trained.

R. Baggio, the Argentinian member of the Commission, together with his South American colleagues continued to organize a series of educational events in connection with the annual meetings of the Argentinian Crystallographic Association; the 2011 meeting was held in the southern village of Bariloche, at the Balseiro Institute (a renowned Physics Centre in Argentina). The main subject of this school was powder diffraction, both from X-ray and neutron sources, and its organization has been partially sponsored by the IUCr.

The Commission met during the Madrid Congress and was involved in the organization of two Microsymposia:

Web-Based Crystallographic Teaching: The Use of Modern Communication Methods to Teach Crystallography; Chair K. Kantardjieff (USA), Co-Chair G. Chapuis (Switzerland); this was a single proposal by the Commission.

Application of Crystal Structure Information in Chemical Education; Chair L. Infantes (Spain), Co-Chair G. Battle (UK); this was a joint proposal by this Commission and the Commission on Structural Chemistry.

P. Spadon and F. H. Allen were the Co-Chairs of a session dedicated to the celebration of nearly 40 years of efforts dedicated to crystallographic teaching by Lodovico Riva di Sanseverino.

\section{K. A. Kantardjieff, Chair}

\subsection{Commission on Crystallography in Art and Cultural Heritage}

The Commission organized two Microsymposia and a Keynote Lecture at the Madrid Congress:
MS46: Powder Diffraction Methods in Archaeometry (Chair P. Bezdicka; Co-Chair C. C. Fernandez);

MS91: X-ray Absorption, Diffraction and Imaging in Forensic Science and Ancient Materials (Chair J. Susini; Co-Chair S. Quartieri);

KN20: From Plane Groups to Quasilattices: Hispano-Islamic Ornamental Art of the Alhambra, Cordoba and Sevilla (E. Makovicky).

The Commission held two Open Meetings. A satellite meeting of the Madrid Congress was also held: Crystallography of HispanoIslamic Art: Visit to the Alhambra in Granada, Granada, Spain, 30 August - 1 September 2011 (lead person E. Makovicky). The palace complex of the Alhambra in Granada (Andalusia) contains the most comprehensive collection of Hispano-Islamic ornamental art at its peak of development and offers examples spanning a wide range from plane groups of symmetry to quasilattices. The two-day excursion from Madrid presented and analyzed ornamental patterns based on simple plane groups, dichroic plane groups, analysis of the Islamic approach to polychromatic patterns, the use of layer groups and onedimensional groups, the conscious combinations of different symmetry principles in one pattern and, finally, two-dimensional decagonal and octagonal quasicrystalline patterns. An afternoon session with presentations and discussion preceded the in situ study of the ornaments the following day.

At the Congress, the IUCr together with the Commission provided a platform to illustrate the important place of crystallography and the multiple aspects of its research at the interface between the arts and the sciences. This call addressed all artists and crystallographers whose work and interests pertain to both the arts and the sciences. Each contributor was invited to submit up to ten visuals (images as well as short animations and movies). A selection of these visuals related to crystallography was presented as a continuous looping slide show during the Congress.

\section{E. Doorhyhée, Chair}

\subsection{Commission on Electron Crystallography}

The year 2011 was a very exciting one for the Commission. A new Chair, Vice-Chair and new members were elected by the General Assembly, and consultants were appointed by the President of the IUCr (the membership is given at http://www.iucr.org/ iucr/commissions/electron-crystallography). Several old sections of International Tables were edited and modified, including those on Convergent-Beam Electron Diffraction and Multiple Scattering (by J. C. H. Spence), and a new section on Electrons is being prepared (by C. J. Gilmore) for the new Volume $\mathrm{H}$ of International Tables on powder diffraction. A Special Issue on New Developments in Electron Diffraction was organized (by P. Moeck) and published in Crystal Research and Technology.

The 2011 Nobel Prize for Chemistry was awarded to D. Shechtman for 'the discovery of quasicrystals' (using electron crystallography techniques). The 2011 Gjønnes Medal for Electron Crystallography was awarded to A. Howie and M. Whelan during the Madrid Congress for 'the development of the dynamical theory of diffraction contrast of electron microscope images of defects in crystals, and other major pioneering contributions to the development and application of electron microscopy, diffraction and spectroscopy of materials'.

Various workshops, summer schools and symposia on electron crystallography and microscopy were organized around the world, and the Commission was directly involved in the following. 
In Europe: The 43rd course of the International School of Crystallography entitled Electron Crystallography: New Methods to Explore Structure and Properties of the Nano World, Erice, Italy, 212 June 2011.

In Asia: The 4th K. H. Kuo Summer School of Electron Microscopy and Crystallography: International Workshop on Advanced Electron Microscopy and Applications in Materials Science, Shenyang, People's Republic of China, 11-15 July 2011.

In North America: Workshop on Advanced Electron Crystallography and Automated Crystal Mapping for Materials Applications, Nashville, USA, 7-11 August 2011 (http://www.microscopy.org/ mandm/2011/); Summer Workshop on Electron Crystallography for Materials Science, University of Oregon, Eugene, USA, 3 August 2011.

In South America: CAPES High Studies School: Electron Diffraction, Federal University of Minas Gerais, Brazil, 12-25 November 2011 (http://www.fisica.ufmg.br/ ediffrac/e_diffrac_ english.html).

The Commission also reorganized its Sub-committees for the next three years.

Sub-committee on Biological Cryo-Electron Microscopy [D. N. Wang (Chair, USA), Y. Fujiyoshi (Japan) and H. Stahlberg (Switzerland)]. The Sub-committee aims to promote teaching of and information exchange in cryo-electron microscopy of biological macromolecules and their complexes, and the combined applications of cryo-electron microscopy with X-ray crystallography, nuclear magnetic resonance spectroscopy, and various biophysical and computational techniques.

Sub-committee on Dynamical Electron Diffraction [J. Etheridge (Chair, Australia), J. C. H. Spence (USA), D. Van Dyck (Belgium) and K. Tsuda (Japan)]. The Sub-committee aims to promote education and research in dynamical electron diffraction and to promote understanding of its importance to crystallography and its relationship to other sciences.

Sub-committee on Electron Crystallography Computing and Software [K. Tsuda (Chair, Japan), A. Stewart (Germany), L. J. Allen (Australia)]. The Sub-committee aims to promote better use of existing software for electron crystallography, exchange useful information, and set up and maintain a repository for free programs.

Sub-committee on Gjønnes Medal [L.-M. Peng (Chair, People's Republic of China), U. Kolb (Germany), J. C. H. Spence (USA), L. D. Marks (USA) and D. van Dyck (Belgium)]. The Sub-committee aims to select the recipient(s) of the Gjønnes Medal among those who have made outstanding contributions to the field of electron crystallography.

Sub-committee on Promotion and International Year of Crystallography [L. Meshi (Chair, Israel), X. D. Zou (Sweden), S. Haigh (UK), K. Balzuweit (Brazil) and J. Neethling (South Africa)]. The Sub-committee was formed following the proposal of the IUCr to make 2014 the International Year of Crystallography (IYCr), and intends to work in parallel both on national and international levels, to suggest ideas both for adults and children. The Sub-committee believes that nowadays when electron crystallography is recognized as a branch of science and structure solution using electron crystallography methods has become publicly accepted, teaching and promotion of electron crystallography at the IYCr will be the next logical step towards further expansion of the science.

Sub-committee on Electron CIF Terms and Electron Diffraction Databases [U. Kolb (Chair, Germany), L. Palatinus (Czech Republic) and X. D. Zou (Sweden)]. The Sub-committee is responsible for setting up a CIF file format suitable for the deposition of structures solved by electron radiation as well as for identifying routes for optimal deposition of raw and processed data. Contact with the IUCr Working Group of Database Users has been established.

Sub-committee on International Tables [J. Hadermann (Chair, Belgium), A. Kirkland (UK), L. D. Marks (USA)]. The Subcommittee has revised volumes of International Tables relevant to the Commission. It remains in place to serve as a contact point for the Commission on International Tables when an issue arises concerning electron crystallography.

The Sub-committee on Precession Electron Diffraction is under development.

The previous Commission home page was maintained by L. D. Marks at http://www.numis.northwestern.edu/IUCR_CEC. It was decided during the Madrid Congress that the Commission's home page should be at the IUCr site, and during the transition period a mirror site would be set up in Mainz, Germany, by A. Stewart.

Lian-Mao Peng, Chair and U. Kolb, Vice-Chair

\subsection{Commission on High Pressure}

2011 was quite busy for the high-pressure community and was dominated by the Madrid Congress and by the tragedy of the great Tokai earthquake in March, which significantly affected the brandnew Japanese neutron facility, J-PARC, including the new highpressure beamline.

The Madrid Congress. The Commission was represented on the Programme Committee of the Madrid Congress by F. Fabbiani. The Commission organized seven scientific Microsymposia, three of which were organized jointly with other Commissions (Inorganic and Mineral Structures, Powder Diffraction and Structural Chemistry). In addition to the Microsymposia, two Keynote Lectures were presented by prominent high-pressure scientists: K. Hirose (Japan) and E. Boldyreva (Russia).

A summary of the high-pressure programme at the Madrid Congress is as follows:

MS5: Non-Ambient Powder Diffraction.

MS12: Non-Covalent Interactions in Molecular Crystals and Biomolecular Systems under Pressure.

MS19: Synthesis, Structure and Properties of Novel Materials at High Pressure.

MS40: Pressure-Induced Phase Transitions.

MS47: Advances in High-Pressure Techniques and Instrumentation.

MS60: Solid State Reactivity.

MS75: Liquids, Amorphous and Nanocrystalline Solids at High Pressure.

KN9: K. Hirose: High-Pressure Geoscience/Mineralogy (with Particular Reference to Post-Perovskite).

KN29: E. Boldyreva: Molecular Crystals at High Pressure.

During the Congress the Commission held a closed meeting. Those in attendance were E. Boldyreva, P. Dera, A. Katrusiak, F. Fabbiani, V. Solozhenko, H. Liu and Y. Katayama. The topics discussed included: candidates for new Commission consultants; plans for the 2012 Commission workshop in Mito, Japan; possible choices for the location of the 2013 Commission workshop; and plans for the third Erice School on High-Pressure Crystallography.

Preparations for the 2012 Commission Workshop in Mito, Japan, 23-27 September. The workshop will feature ten scientific sessions: (1) Crystal structures and phase transitions and dynamic phenomena; (2) Amorphous, liquid, noncrystalline and nanocrystalline phases; (3) Magnetic and electronic phenomena; (4) Organic and biological systems; (5) Water, ice and other molecular systems; (6) Materials 
science; (7) Chemistry; (8) Geosciences and planetary sciences; (9) Theory and computation; (10) Techniques for high-pressure research.

The meeting will coincide with the opening of a high-pressure beamline at the spallation neutron source in J-PARC and will include a tour of the new facility. The workshop will be organized as a joint meeting of the Commission on High Pressure and the Quantum Beam Science Directorate of the Japan Atomic Energy Agency.

Preparations for the 2013 Commission Workshop. The Commission selected the site of the Petra-III synchrotron in Hamburg, Germany, as the location for the 2013 Commission Workshop. The Local Organizing Committee will be chaired by P. Liermann of the highpressure beamline at Petra-III.

Participation in the discussions on Crystallographic Data Standards and Deposition. The Commission was represented by F. Fabbiani and K. Dziubek in the discussions that started at the Madrid Congress.

Plans for the Third Erice School on High-Pressure Crystallography. The Commission proposed to the organizer of Erice Crystallographic Schools, Professor P. Spadon, that a third Erice School on HighPressure Crystallography should be held (following the very successful schools in 2003 and 2009). The third school is tentatively scheduled for 2015 and will be co-directed by F. Fabbiani, R. Angel and K. Dziubek.

\section{P. Dera, Chair}

\subsection{Commission on Inorganic and Mineral Structures}

Members and consultants of the Commission (CIMS) discussed various issues mainly via e-mail and those who attended the Madrid Congress met there in person. Other forms of communication were provided by occasional other meetings or conferences, or by using the web site. The latter is kindly maintained by M. Nespolo (http:// www.crystallography.fr/cims/).

In 2011, J. Rocha became Chair of CIMS succeeding W. Depmeier who remains an ex officio consultant.

The Commission on Structural Chemistry (CSC) and CIMS maintain their links. A. Beatty is the representative for the CSC in CIMS while P. Mercier represents CIMS in the CSC.

P. Mercier continues to act as liaison officer for CIMS with the IUCr Newsletter. He is also the representative of CIMS on the Working Group of Database Users.

Strong links exist between CIMS and Special Interest Group 5 of the European Crystallographic Association (ECA-SIG5, http:// sig5.ecanews.org/). At present, the Secretary of SIG5 is O. Siidra, the Chair is S. Krivovichev and the Vice-Chair is F. Hatert.

There are very good relationships between CIMS and the European Mineralogical Union (EMU, http://www.univie.ac.at/ Mineralogie/EMU/): H. Effenberger is Secretary of the EMU, and R. Oberti, the current Chair, is a member of CIMS.

CIMS was involved in the following meetings held in 2011 and currently in preparation:

The second SMARTER (Structure elucidation by coMbining mAgnetic Resonance, compuTation modEling and diffRaction) Crystallography Workshop, Aveiro, Portugal, 23-27 May 2011 (http:// smarter.web.ua.pt). J. Rocha chaired the Organizing Committee. The event was attended by some 115 researchers, from 12 countries. The IUCr sponsored seven young scientists.

The third SMARTER Crystallography Workshop will be held in Versailles, France, 10-13 September 2012 (http://www.smarter3. uvsq.fr). J. Rocha will be a member of the Organizing Committee.

The 2011 General Assembly of the European Geosciences Union (EGU; Vienna, 3-8 April). R. Oberti was convener of session
GMPV21/GD2.15 on Rock-Forming Minerals: Properties, Information and Constraints on Petrological Processes and Numerical Models.

CCXRDS (XVII International Conference on Crystal Chemistry, X-ray Diffraction and Spectroscopic Studies of Minerals), St Petersburg, Russia, 20-24 June 2011 (http://onlinereg.ru/ccxrds). G. Ferraris and O. Yakubovich were members of the Programme Committee, and O. Yakubovich and W. Depmeier presented Plenary Lectures.

Advances in Inorganic Crystal Chemistry: Non-Conventional Approaches, New Techniques, Structure Modelling and Prediction, RFBR-DFG-CNRS Trilateral Scientific Seminar, St Petersburg, Russia, 24-25 June 2011. O. Yakubovich and W. Depmeier gave oral presentations.

Full-day Rietveld Session at the 60th Annual Conference on Applications of X-ray Analysis (http://www.dxcicdd.com/11/ index.htm), Denver, USA, 1-5 August 2011, organized by P. Mercier.

Madrid Congress. O. Yakubovich gave an oral presentation in the Microsymposium Minerals as Advanced Materials and W. Depmeier gave an oral presentation in the Microsymposium Crystallography of Materials with Exchange, Sequestration and Storage Properties.

Italian two-day symposium celebrating the centennial of X-ray diffraction, co-organized by the AIC and the Accademia Nazionale dei Lincei (Rome, 8-9 May 2012). R. Oberti and G. Ferraris are members of the Organizing Committee. This symposium obtained the patronage of the ECA.

2013 Goldschmidt Conference, Florence, Italy, 25-30 August. R. Oberti is Co-Chair of the theme The Cutting Edge in Mineralogy and Mineral Physics, and a member of the Organizing Committee.

CIMS supported the applications for financial support by the IUCr for the following meetings to be held in 2012:

Gordon Research Conference on Crystal Engineering, Waterville Valley Resort, New Hampshire, USA, 10-15 June 2012 (http:// www.grc.org/programs.aspx? year=2012\& program=crystaleng).

Computational Discovery for Novel Crystal Structures and Advanced Materials Using the USPEX Code, Lausanne, Switzerland, 21-27 October 2012.

Bragg Symposium: Celebrating 100 years of X-ray Crystallography, Adelaide, Australia, 6 December 2012 (http://sapmea.asn.au/ conventions/crystal2012/index.html).

Some additional personal achievements:

W. Depmeier was elected a member of the IUCr Executive Committee where, inter alia, he is responsible for the links between the Executive Committee and CIMS. He continues to be a member of the ECA Executive Committee, probably until the Bergen ECM. He was a member of the International Programme Committee for the Madrid Congress. After Professor F. Liebau passed away (11 March 2011), he became Guest Editor of a special in memorium issue of Zeitschrift für Kristallographie.

G. Ferraris continued as Series Editor of EMU Notes. He was Plenary Lecturer at CCXRDS (XVII International Conference on Crystal Chemistry, X-ray Diffraction and Spectroscopic Studies of Minerals), St Petersburg, Russia, 20-24 July 2011.

F. Hatert was elected as Vice-Chair of Special Interest Group 5 on Inorganic and Mineralogical Crystallography (SIG5) of the European Crystallographic Association (ECA). He works as Associate Editor of the Canadian Mineralogist, and handles the mineralogical nomenclature proposals as Vice-Chair of the Commission on New Minerals, Nomenclature and Classification (CNMNC) of the International Mineralogical Association (IMA). He was co-organizer of the congress entitled 5th International Symposium on Granitic Pegmatites, PEG2011, Mendoza, Argentina, 20-27 February 2011. 
P. Mercier has become a consultant for the Commission on Crystallographic Computing, where he will act as local organizer for the Crystallographic Computing School to be held in Ottawa around the time of the IUCr Congress in Montreal in 2014.

R. Oberti was the Past President of the Italian Crystallographic Association (AIC), and the Italian delegate to the ECA Council meeting and to the Madrid General Assembly. As President of the European Mineralogical Union, she supervised the 2011 EMU School on Layered Mineral Structures and Their Application in Advanced Technologies, Rome, Italy, 9-19 July 2011 (sponsored by the ECA) and the production of the relevant volume of EMU Notes in Mineralogy. She was a member of the Advisory Board of Elements and a member of the Mineralogy/Petrology Research Grant Committee of the Mineralogical Society of America (MSA). As CoChair of the Sub-committee on Amphiboles of the International Mineralogical Association (IMA), she has just submitted the new scheme for the Nomenclature of the Amphibole Supergroup to the Commission on New Minerals, Nomenclature and Classification, CNMNC.

J. Rocha was appointed Chair of the Editorial Board of the European Journal of Inorganic Chemistry and the Royal Society of Chemistry Nanoscience and Nanotechnology Book Series Editor.

O. Yakubovich worked as an Associate Editor of The Canadian Mineralogist. She was selected as a member of the Council of the Moscow branch of the Russian Mineralogical Society.

\section{J. Rocha, Chair}

\subsection{Commission on Magnetic Structures}

The Commission on Magnetic Structures (CMS) of the IUCr was established ad interim by the Executive Committee in January 2011, and confirmed by the General Assembly on 24 August 2011 at the Madrid Congress, with L. Chapon (UK) as Chair, B. Campbell (USA) as Secretary and the following as members: J. Brown (France), D. B. Litvin (USA), V. Petricek (Czech Republic), A. Pirogov (Russia), V. Pomjakushin (Switzerland), J. Rodriguez-Carvajal (France), T. Sato (Japan) and W. Sikora (Poland). J. M. Perez-Mato (Spain) of the IUCr Executive Committee and M. T. Fernandez-Diaz (France) of the Commission on Neutron Scattering were appointed as consultants. Of the 12 members and consultants to the Commission, eight attended the first formal Commission meeting in Madrid on 26 August 2011. [B. Campbell subsequently replaced L. Chapon as Chair.]

The scope of the new Commission's consideration encompasses a broad range of magnetic structure types, including commensurate magnetic structures, modulated and otherwise aperiodic magnetic structures, low-dimensional magnetic structures, disordered magnetic structures, etc.

The original terms of reference presented with the request to create the Commission are as follows:

(1) Establish standards for the description and dissemination of magnetic structures and their underlying symmetries (representations of propagation vector group, 'complete' representation of the group necessary for multi- $k$ structures, three-dimensional magnetic Shubnikov space groups, superspace symmetry, ...), and promote these standards within the IUCr and among other research communities that rely on magnetic structure information.

(2) Develop CIF standards for magnetic structures and promote their use in crystallographic software. This activity will be developed in collaboration with the IUCr Committee for the Maintenance of the CIF Standard (COMCIFS).
(3) Develop a database for magnetic structures based on the sharing of magnetic CIF files.

(4) Cooperate with other IUCr Commissions in establishing and maintaining standards of common interest, such as magnetic symmetry-group tables, magnetic nomenclature and magnetic form factor data.

(5) Encourage communication and cultivate consensus among research communities that have independently developed diverse approaches to characterizing and describing magnetic structures.

(6) Promote the sponsorship and organization of magnetic structure sessions, symposia, workshops and schools at triennial Congresses of the IUCr, at the meetings of its Regional Associates, and at the meetings of other professional societies that tend to rely heavily on magnetic structure information. This should include sessions dedicated to the analysis of neutron scattering data and magnetic X-ray scattering data.

The Commission will initially work to define a minimal description of a magnetic structure that encompasses two broadly divergent ways of thinking: the 'crystallographic' approach that employs magnetic Shubnikov symmetry groups, and the 'propagation vector' approach that treats amplitudes and phases of Fourier components of the magnetic structure. Furthermore, with both of these approaches, one can either parameterize a magnetic structure in terms of traditional atomic coordinates or in terms of irrep basis functions from group representation theory. Because each of these approaches and parameterizations have special areas of application and strong historical precedents, it would be highly desirable to demonstrate how their minimal descriptions can be conveniently interconverted. Beyond this initial focus, the Commission also looked to the future by establishing Sub-committees to study the issue of a new volume of International Tables on magnetic space groups, the creation of a magnetic CIF dictionary, and the development of a magnetic structure database.

Commission members presented workshop components at a variety of meetings in 2011 on magnetic symmetry, magnetic space groups, the symmetry-mode analysis of magnetic structures, and the Rietveld refinement of magnetic structures against neutron diffraction data. These were not specifically organized under the auspices of the ad interim Commission, but substantially furthered its objectives. Concrete plans for future meetings are also included below.

JANA two-day Workshop on the Solution and Refinement of Magnetic Structures at the Institute of Physics, ASCR v.v.i., Prague, Czech Republic 14-15 February 2011 (M. Dusek, J. M. Perez-Mato and V. Petricek).

Symmetry-Mode Analysis Workshop at the Annual Meeting of the American Crystallographic Association, New Orleans, USA, 25 May 2011 (B. Campbell, H. Stokes and J. M. Perez-Mato).

Madrid Congress Satellite Workshop on the Online Edition of International Tables for Crystallography, Bilbao, Spain, 31 August - 3 September 2011 (D. B. Litvin and J. M. Perez-Mato).

9th TOPAS Users' Meeting, Bad Herrenalb, Germany, 8-11 November 2011 (B. Campbell).

JANA half-day Workshop at the Colloquium of the Czech and Slovak Crystallographic Association, Klatovy, Czech Republic, 12 June 2012 (M. Dusek and V. Petricek).

B. Campbell, Chair

\subsection{Commission on Mathematical and Theoretical Crystallography}

Scientific activity in 2011. During 2011 the Commission on Mathematical and Theoretical Crystallography (MaThCryst) organized 
three main activities, besides its direct involvement in the Madrid Congress.

Madrid Congress: one Keynote Lecture (KN03: D. Proserpio: Topological Characterization of Coordination Networks and Metalorganic Frameworks) and three Microsymposia (Beyond SpaceGroup Symmetry in Periodic Structures; Diffuse Scattering in Partially Ordered/Disordered Systems; Topological Correlations and Crystal Structure Interconnections).

ITOnline 2011 - Satellite Workshop of Madrid Congress, Bilbao, Spain, 31 August - 3 September 2011; this was an introduction to the current state and the future developments of the new online edition of International Tables for Crystallography Volume A: Space-Group Symmetry and Volume A1: Symmetry Relations Between Space Groups. The workshop was led by ten lecturers and attended by 29 participants. Didactic material is available from the workshop web site http://www.cryst.ehu.es/ITschool/ under 'Resources'.

A Workshop on Mathematical Crystallography, Manila, Philippines, 2-6 November 2011. This was the first workshop organized by the IUCr in that country and has been a major event for the University of the Philippines. The workshop was led by nine lecturers and attended by 48 participants from several different institutions in the Philippines, but also from Malaysia, Japan and Tanzania. Didactic material is available from the workshop web site http://www.crystallography.fr/mathcryst/manila2011.php and a selection of photographs are available in the ad hoc section of the IUCr web site (http://www.iucr.org/gallery/2011/mathematicalcrystallography-manila).

A Workshop on Crystallographic Software, Tokyo, Japan, 12-16 December 2011. The workshop was an introduction to the approaches and algorithms behind some well known and less well known software packages: Vesta, MoPro, Jana2006, Chardi, Geminography, and also an introduction to the Bilbao Crystallographic Server. The workshop was originally scheduled for May but the earthquake and nuclear accident in Fukushima obliged us to postpone this to December. This has also affected the participation, which was somewhat lower than expected. Didactic material is currently being uploaded on the workshop web site: http://www.crystallography.fr/ mathcryst/tokyo2011.php and a selection of photographs are available in the ad hoc section of the IUCr web site (http://www.iucr.org/ gallery/2011/mathcryst-software).

A fourth activity, a School in Madhia, Tunisia, was scheduled for April 2011 but because of the Arab revolutions this was postponed until April 2012.

Scientific activities in 2012 and later. Planned activities include, at present:

The above mentioned School on Fundamental Crystallography, Mahdia, Tunisia, 9-13 April 2012 (see http://www.crystallography.fr/ mathcryst/mahdia2011.php).

A School on Fundamental Crystallography, Uberlandia, Brazil, 25 November - 3 December 2012 (see http://www.crystallography.fr/ mathcryst/uberlandia2012.php). This is the third school in Latin America organized by the Commission, after those in Havana, Cuba (2007), and Montevideo, Uruguay (2010).

A School on Fundamental Crystallography, Gjulechitza, Bulgaria, 30 September - 5 October 2013 (see http://www.crystallography.fr/ mathcryst/bulgaria2013.php).

Participation in a Sectional Meeting of the American Mathematical Society, within the framework of a special session on Modeling Crystalline and Quasi-Crystalline Materials, has been realized in Tampa, Florida, 10-11 March 2012 (see http://www.ams.org/meetings/ sectional/2188_progfull.html and http://www.iucr.org/gallery/2012/ mathcryst,-tampa for photographs).
Other activities, already mentioned previously but that are currently under discussion:

A workshop in India, under the responsibility of Commission consultant D. Pandey (dates still to be fixed);

A School on Graph Theory in Crystallography and Crystal Chemistry, after the publication of the book with the same title, currently in preparation by J. G. Eon, W. Klee, J. Rutherford and B. Souvignier. This book will be published as a Monograph in Crystallography in the IUCr/OUP Book Series. Copies of the book will be provided to the participants of the school at a reduced price.

A Workshop on the Manifold Description of Modulated Structures and the Use of Differential Geometry to Describe Crystal Structures, proposed by Commission member S. Hyde.

A book on Geometric Algebra in Crystallography, currently under consideration as a Monograph in the IUCr/OUP Book Series.

Commission member H. Sowa is MaThCryst representative on the Diffraction Data Deposition Working Group of the IUCr.

M. Nespolo, Chair

\subsection{Commission on Neutron Scattering}

A large number of events in the field of neutron scattering took place in 2011 where members of the Commission (CNS) were involved as organizers and/or participants. In July 2011 the 5th European Conference on Neutron Scattering took place in Prague, Czech Republic, attracting a large number of participants made up of users of neutron techniques and developers of neutron instruments from large facilities, covering many scientific disciplines. This is one of the three regional meetings of the neutron community where all aspects of the techniques and the application of neutron scattering are covered. The Commission continued being involved in different training courses and schools, such as the 12th Oxford School on Neutron Scattering, the 11th Canadian Neutron Scattering Summer School, and the 5th ILL Annual School on Advanced Neutron Diffraction Data Treatment using the FullProf Suite. The CNS also gave its support to the 6th International Conference of the African Materials Research Society (6th IC-Africa MRS) sponsored by the IUCr.

At the beginning of the year, the Commission web site was created and is being developed mainly with useful information and links for neutron users.

The formation of a Commission on Magnetic Structures was decided by the General Assembly in Madrid; the goal of the Commission is to promote and establish standards in the description and reporting of magnetic structures. The CNS supports this specialized group and has proposed some of its members.

Nevertheless, the main activity of CNS in 2011 was the organization of Microsymposia at the Madrid Congress, some in coordination with other Commissions. On this occasion the Commission held an Open Meeting where the majority of the old and new members were present, together with a number of external participants. During the meeting various aspects of the Commission's activities were discussed and several actions were agreed for the forthcoming triennium - in particular the reinforcement of links with other Commissions related to the use of neutron scattering in readiness for the Montreal Congress in 2014. The members of CNS will continue to contribute at different levels to the promotion of schools and workshops worldwide to extend the use of neutron techniques. It was also decided to increase contributions to Neutron News and the IUCr Newsletter as a link between the neutron users among crystallographers. Several 
actions were also considered with a view to celebrating the International Year of Crystallography.

During the meeting in Madrid, the IUCr set up a Working Group to address the upcoming issues and potentialities of improved diffraction data deposition, and the CNS is collaborating with this initiative.

An important event in 2011 was the large earthquake in northeastern Japan and its tremendous consequences for the whole country. The neutron community was also confronted with the serious damage caused in both the JRR-3M research reactor and the J-PARC spallation neutron source. Different neutron installations over the world offered support and some beam time to try to help the Japanese neutron users. The remarkable efforts of our Japanese colleagues made it possible to overcome enormous difficulties and just one year later the beam currents have returned to the level of those obtained before the earthquake. Moreover, the 1st Asia-Oceania Conference on Neutron Scattering (1st AOCNS) was held in Tsukuba, Japan, as scheduled, with only minor changes in the conference site and the J-PARC tour.

The capabilities of the rest of the neutron laboratories worldwide continued to grow, increasing the number of instruments open to users and offering new possibilities for sample environment. In 2011 the construction of a new neutron beam reactor was proposed in Canada. The new Canadian Neutron Source is to be modelled on the OPAL reactor in Australia.

At the Madrid General Assembly, the composition of the Commission changed in the light of the suggestions from various National Committees. I would like to thank all members of the Commission: those of the period 2008-2011 for their help during the last triennium and, in particular, for their proposals for the programme of the Madrid Congress, and also the new members, who have taken on this role for the next three years.

\section{T. Fernandez-Diaz, Chair}

\subsection{Commission on Powder Diffraction}

Commission meetings. From the perspective of powder diffraction, 2011 was quite notable with the first ever Erice Crystallography School devoted to the subject, and a very high percentage of the Commission membership and consultants were in attendance. The proximity of the Erice meeting to the Madrid Congress had a significant impact on the membership attendance at the Congress, so the major Commission meeting of 2011 was actually held in Erice. Having such a high attendance led to a more interactive meeting than usual, assisted by the venue being an Erice restaurant. A number of subject areas were discussed, one particularly extended one being best (and worst) practice for submitting powder diffraction papers to journals.

For the reasons outlined above, only a handful of Commission members/consultants attended the Madrid Congress, and there was little to discuss in addition other than feedback from the Executive Committee and additional plans for the new Volume $\mathrm{H}$ of International Tables for Crystallography on powder diffraction. The Commission-supported sessions during the meeting all seemed to be well attended and the technical quality was high.

Volume H of International Tables. During the Congress, a meeting of persons involved in the planning and production of Volume $\mathrm{H}$, including the Editors C. J. Gilmore, J. A. Kaduk and H. Schenk, was held. Volume $\mathrm{H}$ will differ from some of the previous volumes in that the contents are being parcelled up into smaller sections for a greater number of contributors. The contents list for Volume $\mathrm{H}$ has been developed over a number of years but an initial list of possible authors for these sections was drawn up in Madrid. Obviously, Volume $\mathrm{H}$ has a significant impact on the work of the Commission so the number of consultants has increased to assist and to maintain representation for some of the major techniques in powder diffraction.

Working Group on Diffraction Data Deposition. An initial meeting of the new Working Group on Diffraction Data Deposition was held towards the end of the Madrid Congress. Unfortunately, the meeting was scheduled at quite short notice and I was unable to attend. This is not a new area for consideration in powder diffraction, and the International Centre for Diffraction Data (ICDD) has been working through issues such as two-dimensional data sets for a number of years. The ICDD representative on the CPD, J. A. Kaduk, was a very appropriate attendee to represent the Commission.

CPD meeting in 2012: Accuracy in Structure Solution from Powder Diffraction Data. Work on making this meeting happen has continued mostly by the local (i.e. European) organizers, namely L. Smrcok, K. Shankland and R. Rizzi. The meeting was originally envisaged as a satellite to the 2012 ECM, Bergen, Norway. However, continuing difficulties forced us to move the workshop to the EPDIC meeting later in the year in Grenoble, France. Given that the original idea was to try to educate a primarily single-crystal audience of some of the pitfalls of obtaining crystal structures from powder-diffraction data, this was a reluctant move but necessary. Work on this meeting is continuing and the satellite web site may be found at http:// www.accuracy2012.sav.sk/. The workshop organizers intend to put together a $C P D$ Newsletter from the material presented at the workshop.

Meeting sponsorship. In terms of the sheer number of applications for Commission support, 2011 was not the busiest year, but the geographical spread was much improved and half of the applications were for schools. Supported applications came from South America, Africa, Europe, Australasia and the Caribbean:

SARX2012, Colombia.

Bragg Centennial Symposium, Australia.

Conference on Applied Crystallography, Poland.

Insubria International Summer School, Italy.

Powder Diffraction and Rietveld Refinement School, UK.

Third African School and Workshop on X-rays in Materials, Senegal.

8th International School on Crystallography and X-ray Diffraction, Cuba.

\section{P. Whitfield, Chair}

\subsection{Commission on Small-Angle Scattering}

Commission meetings and communication. As in previous years, the Commission (CSAS) members communicated by e-mail or during personal meetings at national and international conferences. During the year, routine communications were accomplished by e-mail. At the Madrid Congress, A. J. Allen succeeded J. Skov Pedersen as CSAS Chair and the following new members were welcomed: D. Babonneau, U.-S. Jeng and, as a consultant, D. McGillivray.

Virtually all CSAS members and consultants contribute to the various activity categories in various ways on an ongoing basis. What follows is a summary of some of the highlights for the calendar year, 2011.

Commission activities. J. Trewhella was a member of the International Programme Committee for the Madrid Congress and coordinated with the CSAS members to propose the SAS-focused Keynote 
Lecture given by I. Torriani (see below) and CSAS-sponsored Microsymposia (MS). These were well attended at the Congress. The MS on Industrial Applications of SAXS and SANS to Hard Materials, and Standardization, Validation, and Automation in Modern Biological Small-Angle Scattering, were especially well attended with lively discussions.

CSAS members took note of the new IUCr Working Group on Diffraction Data Deposition (DDWG) and took part in discussion of a CSAS posting to the DDWG Forum site, contributing to a SASoriented posting eventually made in February 2012.

Educational activities. A 32-hour lecture course on the theory and practice of SAS in investigations of supramolecular structures in nanomaterials was given by V. Volkov to undergraduate and postgraduate students of the Scobeltsyn Institute of Nuclear Physics and the Physical Chemistry Department of Moscow State University. A six-hour training course on SAS methods for the investigation of protein macromolecules in solution was prepared for students of Moscow State University. The course is based on state-of-the-art SAS methods developed by SAS Commission members from EMBL (Hamburg) and from Russia. In 2011, 11 sessions were held, involving 28 undergraduate and postgraduate students. V. Volkov and the Institute of Crystallography (Moscow, Russia) group also gave three review lectures on SAS methods in structural research. Four students of the Moscow State University defended their diploma research on investigation of nanomaterials and protein molecules by SAS methods, while three others started SAS-related diploma research in 2011. Three postgraduate students started SAS-related PhD research at the Institute of Crystallography and at the Physical Department of Moscow State University.

I. Torriani presented lectures at the 5th School on Synthesis of Nano-Materials and Sol-Gel Processes, organized by the Center for Nanotechnology Brazil-Argentina, which took place at the University of Buenos Aires, Argentina, September/October 2011. She also presented a Plenary Lecture at the School for Advanced Studies in Crystallization and Crystallography for Latin America - ECRISLA 2011 (November, 2011) in Florianopolis, Brazil, sponsored by the IUCr.

R. Serimaa presented a lecture on SAXS at the MaxLab Summer School on Synchrotron Radiation, and also gave lectures at the University of Helsinki, Finland, on SAXS as part of her lecture course on Synchrotron Radiation in Materials Research, itself part of the Chemistry Department graduate course on Analytical Methods for Polymer Science. She also taught scattering methods at a summer school for undergraduate researchers at the Department of Chemistry, University of Helsinki.

D. Svergun gave educational lectures in 2011 at events in different countries, including Spain, Korea, USA, Russia, Germany, France, Sweden, Italy and Poland.

J. S. Pedersen continued to educate undergraduate and graduate students in small-angle scattering techniques by his lectures at Aarhus University, Denmark, in the courses Biophysical Chemistry 2, Protein Biophysics, and Physical Chemistry of Soft Matter. The course Biophysical Chemistry 2 also includes hands-on applications of SAS to protein samples. J. S. Pedersen also continued to support new users at his laboratory SAXS facility at Aarhus University, Denmark, from the universities and research institutes in Denmark, Scandinavia and the rest of Europe, in addition to continuing to train students and post-docs in the SAS technique in Aarhus.

D. Babonneau presented a lecture at the GISAXS 2011 workshop on GISAXS characterization of self-aligned nanoparticles on nanoripple patterns.
N. Yagi served as a member of the Local Organizing Committee and conducted SAXS beamline practicals, both for the 11th SPring-8 summer school in July 2011, and for the 5th AOFSRR (Asia/Oceania Forum for Synchrotron Radiation Research) Cheiron school at SPring-8, in September/October 2011.

Community-building activities. I. Torriani served on the Programme Committee for the 21st International Congress on X-ray Optics and Microanalysis - ICXOM21, hosted by LNL, Campinas, Brazil, in September 2011.

J. Trewhella and D. McGillivray are Co-Chairs of the Scientific Programme Committee of SAS 2012, to be held in Sydney, Australia, in November 2012. They are assembling the full Scientific Programme Committee for that meeting. It has been decided that the invited speaker programme will include early career researchers, and there are plans for special tutorial-style workshops, e.g. for biomolecular structural modelling and analysis software.

N. Yagi participated in the NSRRC (National Synchrotron Radiation Research Center) SAXS interest group meeting at Hsinchu, Taiwan, in October 2011, and presented a lecture on XPCS experiments. N. Yagi also serves on the International Advisory Panel for SAS 2012.

D. Svergun became a Co-Chair of the Organizing Committee of the Biology and Synchrotron Radiation Conference to be held in Hamburg, Germany, in September 2013. D. Svergun also continued as a deputy Chair of Working Group V (Complementary Methods) of the European INSTRUCT initiative. He also became a deputy coordinator of BioStruct-X, a project funded by the Seventh Framework Programme of the European Commission to support synchrotron access for established and emerging key methods in structural biology, including SAXS. BioStruct-X started in September 2011 for four years and combines the efforts of eleven large-scale facilities across Europe (http://www.biostruct-x.eu/).

In June 2011, J. S. Pedersen stayed for four weeks at the Laboratoire de Physique des Solides, Université Paris-Sud, France, with M. Imperor-Clerc. During the stay he gave a series of seminars in the Paris region on SAS-related studies of complex structures, including surfactant-protein interactions, block copolymer micelles, contrast variation SAXS combined with static light scattering, modelling of inter-particle interaction effects, and even bone nanostructure analysis using position-sensitive SAXS. J. S. Pedersen also gave additional lectures for promoting SAS, especially in Sweden and Norway.

G. Kostorz gives occasional invited talks on scattering methods in materials science and continues to serve as Co-editor for the Journal of Applied Crystallography and Editor-in-Chief of the IUCr journals.

A. J. Allen continues to serve on the SANS Beam-Time Allocation Committee at the NIST Center for Neutron Research. He continues to serve as a Co-editor for the Journal of Applied Crystallography, becoming Deputy Editor in 2011.

Consultant activities. V. Volkov and the Institute of Crystallography (Moscow) continued to consult in 2011 for about ten scientific and engineering institutes in Russia, and the nanoscale features of some 200 samples of different kinds were investigated by SAS on a collaborative basis.

I. Torriani coordinated the installation and training sessions for imagers and crystallization robots acquired for a high-throughput protein characterization and crystallization platform at the National Laboratory for Biosciences, within the Brazilian Synchrotron Facility. This is the only such facility in South America. It was funded by a São Paulo State Research Foundation in August 2010 and was brought into operation in December 2011. 
D. Svergun became a member of the Expert Panel of Skolkovo Foundation (Russia).

J. S. Pedersen continues to serve on the Programme Committee for Synchrotron and Neutron Research (SYNKNOYT) for The Research Council of Norway.

D. Babonneau serves as a member of Peer Review Committee 3 (Matter and Material Properties: Structure, Organization, Characterization, Elaboration) for beam-time allocation at the SOLEIL synchrotron in France.

$\mathrm{N}$. Yagi is advising on the design of the proposed LIX (High Brightness X-ray Scattering for Life Sciences) beamline at NSLS-II, Brookhaven Laboratory, NY, USA, and is also an adviser for the Advanced Soft Material Beamline at SPring-8, Japan, which is a dedicated SAXS beamline for polymer and soft materials science.

Organizational activities. I. Torriani organized a one-day Workshop on Biomolecular Crystallography in February, 2011, preceding the Brazilian Synchrotron Facility (LNLS) 21st Users' Meeting. B. Rupp and K. A. Kantardjieff (USA) were invited lecturers, and the Workshop attracted 100 participants. I. Torriani was also the Local Committee Chair, organizing the biennial meeting of the Brazilian Crystallographic Association as a satellite meeting of the LNLS Users' Meeting.

Chaired by J. Trewhella and also including D. Svergun, a Protein Data Bank Small-Angle Scattering Task Force has been formed. This Task Force will meet in 2012 to discuss whether small-anglescattering-based structures should be deposited in the Data Bank and, if so, with what criteria and validation.

D. Svergun was a main organizer of an EMBO Global Exchange Lecture Course on Structural and Biophysical Methods for Biological Macromolecules in Solution, held late April/May in Beijing, People's Republic of China. There were over 150 applicants, of which 43 were selected. A team of 12 lecturers and tutors, including Commission member J. Trewhella, conducted the course.

J. S. Pedersen serves on the Organizing Committee of the 11th European Summer School on Scattering Methods Applied to Soft Condensed Matter that will be held in Bombannes, Gironde, France, in June 2012.

U.-S. Jeng was a co-organizer of a workshop on Small-angle Scattering and X-ray Photon Correlation Spectroscopy in Soft Matter Research, held in October 2011 at the National Synchrotron Radiation Research Center (NSRRC), Hsinchu, Taiwan. The workshop aimed to promote SAXS and SANS, and their integration/combination with X-ray photon correlation spectroscopy or inelastic neutron scattering as advanced tools for kinetics/dynamics studies in soft matter research. There were 12 overseas and ten domestic invited speakers, from various fields presenting up-to-date progress in polymer physics, polymer composites, biomacromolecules, protein solutions, colloidal solutions, fibrils and food science. There were 385 registered participants. This was followed by a Protein Solution SAXS/SANS Data Analysis Tutoring Session, which attracted more than 50 participants.

D. Babonneau served on the Scientific Committees organizing symposiums at the EMRS Spring and Fall 2011 meetings, respectively, on Protective Coatings and Thin Films, and Stress, Structure and Stoichiometry Effects on the Properties of Nanomaterials.

Technical activities. I. Torriani presented a Keynote Lecture on Structural Characterization of Applied Organic Materials and Soft Matter at the Madrid Congress.

J. Trewhella and D. Svergun (with J. M. Guss and D. A. Jacques) have co-authored a paper that will appear in Acta Crystallographica Section D, on Publication Guidelines for Structural Modelling of Small-Angle Scattering Data from Biomolecules in Solution.
In 2011, D. Svergun's group provided the community with a 2.4 release of ATSAS, a program package for SAS data analysis. Test access to several programs using GRID resources within the WeNMR project (http://www.wenmr.eu) was established.

Various SAS-related review articles were published in 2011 by D. Svergun and V. Volkov.

The laboratory SAXS instrument at Aarhus University, Denmark, operated by J. S. Pedersen, was upgraded with new home-built 'scatterless' slits in 2011, which led to an effective improvement of the flux by almost a factor of 10 . This has increased the capacity of the instrument and means that more extensive measuring programs can be conducted.

Following successful work on a prototype NIST standard reference material (SRM) for SAXS intensity calibration, based on glassy carbon, A. J. Allen, in collaboration with others at NIST and at the Advanced Photon Source, Argonne National Laboratory, commenced full-scale development of a production version, intended for issue in early 2013. A. J. Allen has also continued to contribute to successive drafts of an ISO TC24/SC4 (Particle Size Committee) SAXS particle size (best practice) standard. Activities remain ongoing.

\section{A. J. Allen, Chair}

\subsection{Commission on Structural Chemistry}

A meeting of most of the old and new members of the Commission (CSC) took place in Madrid on 24 August, in which those present exchanged points of view concerning the working procedure of the Commission, the special tasks to be assumed by Commission members, and future projects and objectives of the Commission. A. Beatty will remain as the link from the CSC to the Commission on Inorganic and Mineral Structures (CIMS), while P. Mercier will act as the link from CIMS to CSC. J. L. Flippen-Anderson is the link to the IUCr Newsletter. As a novelty, the inclusion of a representative from the crystallographic industrial community was approved as consultant for the Commission (O. Almarsson); the idea is that this particular member could help the Commission to detect shared interests between academia and industry in the field of chemical crystallography. An internal debate within the Commission was planned to assign particular duties for the rest of the Commission members.

Commission activities. The major activity of the Commission during 2011 was to make the programme of the Madrid meeting a great success from the point of view of structural chemistry. Apart from the official programme, where at least 12 Microsymposia covered all areas of structural chemistry, the Commission was involved in the preparation of some of the most interesting satellite events.

A quite interesting workshop on Categorizing Halogen Bonding and Other Non-Covalent Interactions involving Halogen Atoms was carried out in Sigüenza (a town close to Madrid), lasting two whole working days. More than 100 specialists in the area took part in this workshop, where a comprehensive look at intermolecular interactions involving halogens as electrophilic species was carried out. This meeting tried to give a modern definition of halogen bonding, taking into account all current experimental and theoretical pieces of information on both gaseous and condensed halogen-bonded systems in chemical and biological systems.

Another relevant activity supported by the Commission was a short workshop on Current Research on Molecular Structures and Chemical Properties - A Young Perspective on 22 August. This event, proposed by the ECA Special Interest Group 13 (SIG13), and 
organized in collaboration with the General Interest Group of Young Crystallographers (GIG-YC), aimed to encourage the exchange of current experiences between different groups working in the connectivity of structures with macroscopic chemical properties. More than 70 young researchers took part in this meeting.

In collaboration with the Commission on Charge, Spin and Momentum Densities, CSC supported an International School on Charge Density, Jaca, Spain, 30 August - 4 September 2011. This School covered all aspects of the methods, from data-collection procedures, through accurate high-order X-ray diffraction experiments to the analysis of derived properties and to their extension to proteins and heavy atoms.

Being sensible to other IUCr initiatives, some Commission members are participating in and contributing to the Working Group on Diffraction Data Deposition. All information from this group has been exchanged among Commission members and J. L. FlippenAnderson and F. J. Lahoz will be representing the CSC at the ACA and ECA workshops, respectively, that will take place in the summer of 2012.

During the last three months of the year, the new Commission has given unanimous written support to two relevant scientific initiatives that will be held during 2012: the 2012 Gordon Research Conference - Crystal Engineering, Waterville, New Hampshire, USA, June 2012, organized by Robin D. Rogers to be held in June 2012, and Indaba 7, Kruger National Park, South Africa, September 2012, organized by Len Barbour.

At the time of writing this report, the Commission is facing discussion of some ideas that arose in the past year, and that are of tremendous interest to the Commission: for example, definitive tasks for each member of the Commission, the convenience of the existence of an IUCr-supported International School on Structural Chemistry, analysis of the different strategies to stimulate publication in Acta Crystallographica Section B, and the preparation of a list of activities for IYCr 2014.

\section{F. J. Lahoz, Chair}

\subsection{Commission on Synchrotron Radiation}

The aim of the Commission is to promote access and awareness of crystallographers worldwide to the world's synchrotron-radiation (SR) facilities. To this end, the Commission broadly promotes the development of crystallographic instrumentation, technology and standards, and the synergies between storage-ring-based and LINACbased next-generation sources such as X-ray free electron lasers (X-FELs) and energy recovery linacs (ERLs).

The Commission notes the continued progress made by several XFEL projects including FLASH in Germany and LCLS in Stanford, which are fully operational, and the successful commissioning of the FERMI (Italy) and SACLA (Japan) facilities. Furthermore, new FEL projects are underway in many countries. In response to these developments the Commission has decided to invite a consultant from the three major XFEL facilities: the European XFEL, LCLS and SACLA.

The Commission also notes the continued high levels of investment and development in new storage-ring-based SR facilities, and in upgrade projects to existing facilities. These include construction of new large high-brightness facilities at Brookhaven (NSLS II) and Taiwan (the Taiwan Photon Source), the re-dedication of the PETRA storage ring as a light source, and upgrade projects at ESRF, APS and SPring-8. Thinking is underway at a number of laboratories towards the goal of a diffraction-limited (at crystallographic X-ray energies) 'ultimate light source' storage ring.

Membership. The outgoing Chair (S. Wakatsuki) and proposed new Chair (R. F. Garrett) represented the Commission at the IUCr Executive Committee meeting at the Madrid Congress. The Commission triennial report was presented, and the proposed new membership was approved by the Executive Committee (and subsequently by the General Assembly). The present membership of the Commission may be found at http://www.iucr.org/iucr/ commissions/synchrotron-radiation. The General Assembly approved an increase in the membership by 1 , to even out representation from the three major regions (Europe, USA and Asia-Oceania), and the inclusion of additional consultants to bring expertise on the X-ray free-electron laser facilities into the Commission. T. Tschentscher from the European X-FEL has accepted to be nominated for consultant membership and discussions are underway with SACLA (Japan) and LCLS (USA) for suitable consultant members.

Madrid Congress. The Commission organized Microsymposium 37 on X-ray Lasers and Other New Frontiers in Synchrotron Applications to Structural Science, in which the latest developments in the utilization of the new-generation photon sources were presented. The Microsymposium was chaired by Commission members S. Wakatsuki and J. L. Smith, and comprised five invited oral presentations covering topics from ultra-fast protein dynamics to progress towards the goal of structure determination from single-molecule diffraction. In addition, 12 posters were presented in the associated poster session. S. Pascarelli, a former consultant and now full member of the Commission, played an important role as a member of the International Programme Committee for the Congress.

The Commission also held an Open Meeting during the Congress, on 26 August, which was attended by 20 Commission members and Congress delegates. Issues discussed included the recognition of beamline scientists, which is a particular concern in the case of protein crystallography beamline staff, and is increasingly a matter of concern generally. The offer by the Journal of Synchrotron Radiation to publish short-format beamline papers was agreed to be a positive development. J.-L. Hodeau presented a multi-language display on crystallography, which had been developed for the International Year of Chemistry and which will be updated for the International Year of Crystallography (see additional reference in Other activities section). It was noted that one combined Microsymposium proposal was accepted for the Madrid Congress: SRXAS. The meeting agreed that additional joint sessions should be proposed for the next Congress, for example synchrotron-neutron combined methods and cultural heritage applications. The Commission agreed to propose such symposia to the International Programme Committee for the Montreal Congress.

Q2XAFS workshop. Q2XAFS, the International Workshop on Improving Data Quality and Quantity for XAFS Experiments, was held in December 2011, hosted by the Photon Factory, Japan, and coorganized by the IUCr Commissions on XAFS and Synchrotron Radiation, IXAS (the International X-ray Absorption Society), the KEK IMSS (Institute of Materials Structure Science) and JXS (the Japan XAFS Society). The Workshop was originally planned for April 2011, but was postponed following the disastrous earthquake and tsunami which struck eastern Japan on 11 March 2011. The venue, the KEK Laboratory in Tsukuba, was significantly damaged, and the workshop was postponed until December.

Two reports on recommendations about standards and criteria for XAFS were published in 1992 and 2000. However, the new thirdgeneration synchrotron-radiation sources have enabled high quality 
and throughput XAFS measurements as well as new types of experiments. These new developments require new standards and criteria for XAFS spectroscopy, and this need was the driving force behind the Q2XAFS workshop.

The aim of the workshop was to establish new standards and criteria for XAFS experiments and analyses as well as to establish a new data format, and a database for data deposition. It also included discussions on new developments in experimental procedures and requirements on the third-generation SR sources, and also on future light sources. It was attended by 71 people, including 25 from outside Japan (USA, UK, France, Italy, Germany, Canada, Australia, Korea, People's Republic of China and Thailand). The workshop was held with five oral sessions and one poster session.

A working group open to any interested participant was established at the workshop to continue the work on new standards. The workshop report will be published in the Journal of Synchrotron Radiation, and discussions will continue at XAFS15 in Beijing, People's Republic of China, in 2012.

Supported meetings, schools and workshops. During 2011 the Commission provided letters of support and endorsement for the following meetings:

The RapiData course on automated data collection at NSLS, Brookhaven National Laboratory, NY, USA, 3-8 April 2011. We encouraged the organizers to support participation of Latin American students.

International School/Conference on Resonant Elastic X-ray Scattering in Condensed Matter, Aussois, Savoie, France, 13-17 June 2011, and the VIII edition of the School on Crystallography and X-ray Diffraction, Havana, Cuba, 21-26 November 2011.

The International Workshop on New Developments of Methods and Software for Protein Crystallography, Xi'an, People's Republic of China, 25-27 August 2012.

The Sagamore XVII Conference, Kitayuzawa, Hokkaido, Japan, 15-20 July 2012.

The International Conference on Small-Angle Scattering (SAS 2012), Sydney, Australia, 18-23 November 2012.

AsCA '12/CRYSTAL 28 and the Bragg Symposium, Adelaide, Australia, 2-6 December 2012.

In general, the Commission has strongly supported IUCr sponsorship for the purpose of assisting attendance by young researchers and scientists from developing countries.

Other activities. Shih-Lin Chang from the Commission was involved in organizing the Taiwan-Japan Joint Seminar on Crystallography 2011, Department of Chemistry, National Taiwan University, 7-8 November 2011. Around 80 participants attended the Seminar, among which were ten lecturers from Japan and ten from Taiwan. Synchrotron-radiation applications in crystallography were a main focus of the Seminar. This was the tenth of the series of Joint Seminars, which have been held every two years.

J.-L. Hodeau has played a key role in planning a number of European activities to celebrate the centenary of the Laue-Bragg discoveries. Several European and French Institutions from Grenoble (Institut Laue Langevin, European Synchrotron Radiation Facility, CNRS, CEA, Université J. Fourier, Grenoble-INP, SiMAP, Institut Neel, INAC, GIANT, School Rectorat, Science-Musée La Casemate, a museum, schools, French Association of Crystallography) have formed a joint committee to try to coordinate different events designed for different audiences (scientific workshops, activities in schools and, if possible, a large public exhibition). For the general public, this event will be called Le monde á l'envers, 100 ans de cristallographie - ou comment voir le cristal, la matière, la vie.
A Laue celebration will be first organized (in English) on 13 November 2012, under the auspices of the Institut Laue Langevin, which will also include a light exhibition on the Laue-Bragg discovery. During the European Powder Diffraction Conference (EPDIC), there will be one dedicated Keynote Lecture at the Opening Ceremony on 28 October 2012, and the same exhibition on the Laue-Bragg discovery will be presented. This light exhibition on the Laue-Bragg discovery will be translated into different languages and a large public event (in French) will be organized in 2013.

The Commission will promote and be actively involved in various additional activities related to the 100th year of X-ray crystallography and the International Year of Crystallography. The joint AsCA '12CRYSTAL 28 Conference and the associated Bragg Symposium will be held in December 2012 in Adelaide, Australia, and S. Wakatsuki is a member of the International Science Advisory Committee. The next International Conference on Structural Genomics (ICSG) will be held in Tsukuba, Japan, in 2013 (S. Wakatsuki will Chair the Organizing Committee) and will include a special session on the 100th year of X-ray crystallography.

The sixth Asia-Oceania Forum for Synchrotron Radiation Research (AOFSRR) Conference was planned to be held in Bangkok, Thailand, in October 2011, but was cancelled owing to the devastating Thailand floods. The Conference has been re-scheduled for 8-12 August 2012. Commission members R. F. Garrett and ShihLin Chang are members of the Organizing Committee.

The 4th Workshop on XFEL Science was in Cairns, Australia, 29 August - 2 September 2011. Commission Chair R. F. Garrett served on the Organizing Committee. The XFEL science series is primarily an Asia-Oceania workshop, endorsed by the AOFSRR, and focuses on the proposed scientific programmes of the new XFEL facilities, in particular the SACLA facility currently being commissioned at SPring-8. A Memorandum of Understanding was signed at the meeting between the RIKEN SPring-8 Centre and ANSTO on behalf of the Australian Collaboration for Accelerator Science, to facilitate collaborative research in applications of next-generation light sources, joint research on RIKEN facilities and exchange of scientists and engineers.

\section{R. F. Garrett, Chair}

\subsection{Commission on XAFS}

The Commission worked hard in 2011, as exemplified by the XAFS Workshop at the Madrid Congress and the Q2XAFS meeting, which was fully coordinated by the IUCr Commissions on XAFS and Synchrotron Radiation, and by IXAS. A Special Issue of Journal of Synchrotron Radiation will be dedicated to XAFS and this is an important achievement for the XAFS community and for our Commission, as several members contributed to this issue.

Two Commission meetings were held (one in Madrid and one in Tsukuba) to coordinate financial requests for support, together with a circular e-mail meeting and response, to confirm support by the Commission for the XAFS15 and ISPR conferences. It has taken some time to interact with the two targeted conferences, in particular with XAFS15, but the projects are progressing. These conferences are directly linked to our IUCr goals concerning the scientific content and high-profile activity of leadership. On behalf of our Commission, Chris Chantler has kindly accepted to take charge of joint sessions with the organizers of XAFS15 and ISRP; these sessions are specifically devoted to Commission and IUCr objectives.

\section{Ascone, Chair, and C. T. Chantler, Secretary}




\section{Sub-committee on the Union Calendar}

The Sub-committee receives and considers requests for IUCr sponsorship and nominal financial support, and makes recommendations to the Executive Committee. Acting on the recommendations made by the Sub-committee, during 2011 the Executive Committee approved sponsorship of various schools and meetings, mostly with financial support. Those held in 2011 are listed at the beginning of this Report of the Executive Committee. Those scheduled for 2012, but approved in 2011, are listed below.

Third African School and Workshop on X-rays in Materials: Some Established Techniques and Practical Applications, Dakar, Senegal, 23-28 January 2012.

Powder Diffraction and Rietveld Refinement School, Durham, UK, 25-29 March 2012.

RapiData 2012, Brookhaven, USA, 22-27 April 2012.

From Genes to Atomic Structures: an Introduction to Synchrotron-Based Structural Biology, Trieste, Italy, 23-27 April 2012.

3rd International School on Crystallization: Drugs, Foods, Agrochemicals, Minerals, New Materials (ISC2012), Granada, Spain, 2125 May 2012.

Present and Future Methods for Biomolecular Crystallography, Erice, Italy, 31 May - 10 June 2012.

2012 Gordon Research Conference: Crystal Engineering, Waterville Valley Resort, New Hampshire, USA, 10-15 June 2012.

Electron Crystallography School - New Methods and Applications, Stockholm, Sweden, 17-20 June 2012.

Fourth European Conference on Crystal Growth (ECCG4), Glasgow, UK, 17-20 June 2012.

Insubria International Summer School on Crystallography for Health and Biosciences, Como, Italy, 19-23 June 2012.

Sagamore XVII - Great Potentials from Advanced Probes, Hokkaido, Japan, 15-20 July 2012.

Annual Meeting of the American Crystallographic Association, Boston, USA, 28 July - 1 August 2012.

27th European Crystallographic Meeting, Bergen, Norway, 6-11 August 2012.

Aperiodic 2012, Cairns, Australia, 2-7 September 2012.

Computational Discovery for Novel Crystal Structures and Advanced Materials using the USPEX Code, Lausanne, Switzerland, 21-27 October 2012.

International School on Fundamental Crystallography 2012 (ISFC 2012), Uberlandia, Brazil, 25 November - 2 December 2012.

Organizers of meetings wishing to seek IUCr sponsorship should submit applications at least nine months in advance of the meeting, writing to the Chair of the Sub-committee. The present Chair is Professor J. M. Perez-Mato. For up-to-date contact information, application procedures and rules, see http://www.iucr.org/iucr/ sponsorship/meetings.html.

Applications for sponsorship of satellite meetings require the approval of the Chair of the Organizing Committee of the main meeting. Meetings (other than satellite meetings) scheduled to be held within one month before or after an IUCr Congress will not be considered for sponsorship. For any meetings (other than meetings of Regional Associates) scheduled to be held between one and two months before or after a Congress, the application for sponsorship will be sent to the Chair of the Congress Programme Committee for approval, or otherwise. For meetings (other than satellite meetings) scheduled to be held, in the respective region, within one month before or after a meeting of a Regional Associate (American Crystallographic Association, Asian Crystallographic Association,
European Crystallographic Association), the applicants for sponsorship must seek approval of the Chair of the Regional Associate Organizing Committee.

The IUCr continues to support and uphold ICSU's policy of non-discrimination and adheres to its decisions and procedures concerning the free circulation of scientists. Organizers of any meetings seeking IUCr sponsorship or support must assure the Subcommittee on the Union Calendar that the authorities of the country in which the meeting is to take place guarantee free entrance of bona fide scientists from all countries.

\section{Committee for the Maintenance of the Crystallographic Information File Standard (COMCIFS)}

COMCIFS is charged with maintaining and developing the Crystallographic Information Framework (CIF), which includes syntax and dictionary language standards as well as a number of dictionaries written according to these standards. 2011 was the 20th anniversary of the original publication describing CIF and its adoption by the IUCr as a standard data-transfer framework. In recognition of this anniversary, COMCIFS sponsored a lively Microsymposium at the Madrid Congress devoted to data transfer and archiving, past, present and future.

At the beginning of 2011, COMCIFS was still preoccupied with ironing out a few syntactical features of the new CIF syntax standard ('CIF2'), with decisions regarding a new dictionary language ('DDL3') also pending. Significant progress on these fronts was made at the Madrid Congress: CIF2 was approved for use in dictionaries, in the expectation that any problems would be caught at this dictionary stage prior to expanding CIF2 use to include data files. DDL3 was also accepted, subject to a successful pilot test at the IUCr offices. As the year drew to a close, rewritten core dictionaries using DDLm and CIF2 were being prepared for testing.

Other COMCIFS initiatives arising out of the Madrid Congress included:

(1) devolution of more autonomy to dictionary management groups;

(2) development of a standard CIF programming library (API);

(3) development of a name-space mechanism for CIF dictionaries;

(4) clarification of the copyright status of CIF documentation.

COMCIFS-sponsored dictionaries continue to be developed. Together with continuing small updates to the core dictionaries using the new 'fast-track' procedure, a new constraints-restraints dictionary for use with the core dictionary was approved. Considerable attention was focused by several Keynote speakers in Madrid on the lack of CIF data names for describing twinned crystal refinements. A project to provide these data names is well underway and should be finalized in 2012.

John Bollinger was welcomed as a COMCIFS voting member this year following Nick Spadaccini's resignation as a voting member last year.

\section{J. Hester, Chair}

\section{IUCr Newsletter}

All issues of Volume 19 were 24 pages in length. As in previous years, the content covered topics such as activities of the IUCr, its Regional Associates and Commissions, Letters to the Editor, news concerning crystallographers and crystallography in general, awards, election 
results, resources, meeting reports, book reviews, future meeting announcements, and a general meeting calendar.

Each issue carried a President's column, two written by Sine Larsen and two written by Gautam Desiraju. Editorial responsibilities were shared by Bill Duax and Judy Flippen-Anderson. Patti Potter was responsible for layout and all phases of production and distribution.

Each issue devoted at least two pages to brief summaries of selected articles recently published in IUCr journals. Issue 1 highlighted the 2009 annual meeting of two of the three Regional Associates (ACA and ECA). Issues 2, 3 and 4 contained a special report on Crystallography in South-Eastern Europe. Issues 3 and 4 contained the first reports from the Madrid Congress.

Additional meeting and workshop reports were published covering activities in Germany, Hungary, Japan, Morocco, Slovenia, South Korea, UK, Uruguay and the USA. Future meeting announcements covered the Madrid Congress as well as meetings in Austria, Italy and the USA.

The mailing list for the first three issues averaged 19000 , which is an increase of $4 \%$. We sent Issue 3 to a limited number of people as a test for the electronic distribution. It was well received and we distributed Issue 4 to the bulk distribution list (3741). Twenty countries assisted in distribution of the Newsletter. (Distributors: H. Fodil: Algeria; P. Jensen: Australia; J. Valderrama: Colombia; B. KojicProdic: Croatia; J. Hasek: Czech Republic; A. Nangia and Executive Secretary: India; Ismunandar: Indonesia; P. Spadon: Italy; CrSJ: Japan; A. Hamid Othman: Malaysia; J. Lipkowski: Poland; M. Costa: Portugal; W. Klooster: Singapore; L. R. Nassimbeni: South Africa; J. Schefer: Switzerland; Yu Wang: Taiwan; K. Haller: Thailand; H. Kooijman: The Netherlands; G. Diaz de Delgado: Venezuela.) Individual distribution was sent to 84 additional countries.

W. L. Duax and J. L. Flippen-Anderson, Editors, P. Coley, Production Manager

\section{IUCr/Oxford University Press (OUP) Book Series}

In 2011, the cooperation between Oxford University Press (OUP) and the IUCr/OUP Book Series Selection Committee was quite productive.

A new volume has been published in the Monographs on Crystallography series:

No. 25: Neutron Protein Crystallography - Hydrogen, Protons, and Hydration in Bio-macromolecules, by N. Niimura and A. Podjarny (published 17 February 2011).

Three new volumes have been published in the Texts on Crystallography series:

No. 15: Fundamentals of Crystallography, third edition, by C. Giacovazzo, H. L. Monaco, G. Artioli, D. Viterbo, M. Milanesio, G. Ferraris, G. Gilli, P. Gilli, G. Zanotti and M. Catti (published 10 February 2011).

No. 16: Electron Crystallography: Electron Microscopy and Electron Diffraction, by X. Zou, S. V. Hovmöller and P. Oleynikov (published 18 August 2011).

No. 17: Symmetry in Crystallography: Understanding the International Tables, by P. G. Radaelli (published 22 September 2011).

A number of new books are in the production phase and others are in the pipeline. The Committee and the OUP editing staff reviewed a number of proposals and there are contacts with authors about possible new volumes.

The Committee is very interested in proposals for new volumes and encourages prospective authors to contact the Chair of the
Committee (davide.viterbo@mfn.unipmn.it). Readers may suggest topics and/or authors, as they know the subjects that are not well covered in the literature. Manuscripts covering important aspects of crystallography and related fields are very welcome.

D. Viterbo, Chair of Book Series Selection Committee

\section{Regional Associates and Scientific Associates}

\subsection{American Crystallographic Association (ACA)}

The 2011 ACA Council included T. Koetzle (President), G. Phillips (Vice-President), J. Kelly (Past-President), B. Santarsiero/S. N. Rao (Treasurer) [B. Santarsiero resigned as ACA Treasurer and Chief Financial Officer; S. N. Rao took over his duties for the remainder of his elected term], C. Wilmot (Secretary) and J. Davis [ex officio, Young Scientists Scientific Interest Group (YSSIG) representative]. D. Rose served as the Canadian representative, W. L. Duax as Chief Executive Officer and M. L. Hackert as IUCr representative. The ACA Council met twice in 2011: a spring meeting on 27 May in conjunction with the Annual Meeting in New Orleans, and a fall meeting in Buffalo on 21-22 October. The paid membership of the ACA was about 1700 by fall of 2011, down slightly from 1840 paid members in the fall of 2010 .

ACA New Orleans. The highlight of the year was the ACA Annual Meeting held in New Orleans, 28 May - 2 June 2011. The Programme Chair for this meeting was C. Cahill, with E. Stevens and C. Stevens serving as Local Chairs, and I. Guzei as Poster Chief. The meeting was a success with about 216 posters and 394 lectures and about 650 participants, which was excellent considering that ACA meetings during IUCr years are always smaller. Attendees travelled from 27 different counties with $20 \%$ of the total participants coming from outside the USA. Young scientists (students and post-docs) represented $32 \%$ of the total meeting attendance.

The New Orleans meeting featured two, full-day workshops - one on Symmetry-Mode Analysis and another on an Introduction to PHENIX for Beginning to Advanced Crystallographers. The conference also featured an ACA Transactions Symposium in honour of P. Coppens in conjunction with his 80th birthday. The morning session was on Time-Resolved Studies and Photochemistry, and the afternoon session on Time Resolved and Charge Density. ACA's Canadian Division organized a session on Evolution of Powder Diffraction Software in honour of L. M. D. Cranswick.

Also featured in New Orleans were five Plenary Lectures. The 2011 Patterson Award lecture was given by K. Moffat who spoke on his work in the area of time-resolved crystallography. The 2011 Wood Science Writing Award went to D. Nocera, who will deliver his talk in Boston in 2012. D. J. Watkin was selected as the 2010 Fankuken Awardee for his stewardship of the crystallographic software package CRYSTALS. He was unable to be in Chicago and accepted his award in New Orleans. The 2011 Margaret C. Etter Early Career Award went to Y. Mozharivskyj, who discussed efforts to form guiding principles for the design of new magnetocaloric materials. Finally, N. C. Seeman delivered a plenary lecture on DNA: Not Merely the Secret of Life.

The ACA Council announced a number of important actions in New Orleans:

The Inaugural Class of ACA Fellows. The Fellows Programme was organized to recognize a high level of excellence in scientific research, teaching and professional duties, as well as service, leadership and personal engagement in the ACA and the broader world of crystallography and science. The first group of ACA Fellows are: H. 
Berman, P. Coppens, J. Deisenhofer, W. L. Duax, J. L. FlippenAnderson, J. P. Glusker, H. Hauptman, W. A. Hendrickson, C. K. Johnson, I. Karle, J. Karle, S. N. Rao, C. Rajnak, M. G. Rossmann, G. M. Sheldrick and B. C. Wang.

Summer schools. The ACA Council has selected Notre Dame and Northwestern to host the ACA Summer Course in Small Molecule Crystallography for 2012-2015. The courses will be organized by A. Oliver (Notre Dame) and A. Sarjeant (Northwestern). To encourage the ability of the ACA to support courses that teach the fundamentals of X-ray crystallography for both small-molecule and macromolecular crystallography, the ACA has established a new fund to support the offering of these courses.

ACA History Fund. V. Pett has compiled a series of Living History articles that have been published in RefleXions. The full documents with references have been archived in the AIP History Center Niels Bohr Library \& Archives (NBL\&A). The ultimate goal will be to make everything available online through the ACA History Portal. In addition to the Living Histories, the Portal is envisioned as containing obituaries, ACA award lectures, focus articles and other items of historical interest. The ACA has created a new fund, the ACA History Fund, to cover the cost of supporting the initial creation of the site, its development and continued maintenance.

Other. A team headed by J. Davis (YSSIG representative) has created a LinkedIn web site for the ACA, and the ACA is also now on Facebook! The ACA Council also expressed its interest in the formation of a Latin-American Division within the ACA analogous to the Canadian Division. This division could then elect a voting member to the ACA Council.

Future meetings. Upcoming ACA Annual Meetings include 2012 in Boston (28 July 28 - 1 August) with Programme Chairs B. Foxman and B. Noll, Poster Chair I. Guzei, and Local Chair P. Müller. The Boston meeting will use a four-day format with scientific sessions running from Sunday through Wednesday. The 2012 Award winners are J. C. H. Spence of Arizona State (Buerger), P. Fenter of Argonne (Warren), D. Nocera (Wood), R. Hamlin of Area Detector Systems Corp (Supper) and E. Skordalakes (Etter). The 2013 ACA meeting will be in Hawaii, 20-24 July.

Elections. The fall 2011 elections resulted in C. L. Stevens, Dean of Science and Engineering at Western Kentucky University, as the 2012 ACA Vice-President, P. Loll (Drexel University) elected Secretary, E. Snell (Communications), A. Sarjeant (Continuing Education Committee) and J. D. Westbrook (Data, Standards and Computing), plus new Chairs elected to head the 12 SIGs.

On a sad note, the ACA lost a number of outstanding members during 2011, including the Colonel, William Lipscomb Jr (1969 Nobel Laureate) who left us on 14 April 2011, at the age of 91, and Herb Hauptman (1985 Nobel Laureate) who died on 23 October 2011 at the age of 94 .

\section{L. Hackert, IUCr Representative}

\subsection{Asian Crystallographic Association (AsCA)}

The AsCA Executive Committee during 2011 is: Se Won Suh (Korea), President; J. M. Guss (Australia), Immediate Past-President; P. Chakrabarty (India), Vice-President; A. Vrielink (Australia), Secretary/Treasurer; M. A. Spackman (Australia), Trustee. J. M. Guss was selected at the IUCr General Assembly in Madrid to serve as IUCr representative for AsCA.

AsCA meetings. In 2011 no AsCA scientific meeting was held, because in the triennial cycle AsCA meetings are not held in the same year as an IUCr Congress.
Council meeting. The AsCA Council Meeting was held in Madrid, Spain, 26 August. The IUCr President, S. Larsen, gave a brief overview of IUCr activities, including the plans for the International Year of Crystallography (IYCr). M. Ahmed (Pakistan) reported that Pakistan will hold their first crystallographic meeting in October with the support of the IUCr. R. Withers and S. W. Wilkins presented progress reports on the organization of the AsCA 2012/SCANZ meeting and the Bragg centenary symposium. A. Hussain (Bangladesh) and Duong Ngoc Huyen (Vietnam) presented proposals to host the AsCA 2013 meeting. The Council selected Bangladesh as the site for AsCA 2013 following a close vote. Other items discussed at the Council meeting included possible activities related to IYCr, solicitation of new AsCA members, confirmation of the 2007 Council meeting, proposals for revision of the Constitution, payment of the AsCA group member to the IUCr (presently Bangladesh, Malaysia, Singapore, Thailand and Vietnam), and the maintenance/upgrade of the AsCA home page.

The schedule for future scientific meetings of AsCA is therefore as follows:

AsCA 2012 meeting: Adelaide Convention Centre, Adelaide, Australia, 2-6 December 2012. The joint AsCA/SCANZ conference (2-5 December) will be followed by a one-day symposium to celebrate the centenary of the presentation of Lawrence Bragg's paper to the Cambridge Philosophical Society. It was this paper that first defined the Bragg equation. The Bragg symposium will be a public forum with speakers including descendants of Lawrence Bragg, his former students, and high-profile scientists. The Chairs of the Organizing and Programme Committees for the AsCA meeting are J. Carver and J. Varghese, and S. W. Wilkins is organizing the Bragg symposium.

AsCA 2013 meeting: Dhaka, Bangladesh, 1-4 December 2013. The Chair of the Programme Committee is T. Kamiyama (Japan) and the Chair of the Organizing Committee is A. Hussain (Bangladesh). This will be the first time an AsCA meeting will be held in Bangladesh in keeping with the mission of the Association to expand the reach of crystallography throughout the Asian region.

AsCA 2015 meeting: India, to be held jointly with the Indian Crystallographic Association. This meeting will provide useful preparation for the IUCr Congress to be held in Hyderabad, India, in 2017.

The location of the 2016 AsCA meeting will be discussed by the Council at their meeting in Adelaide in December 2012. Expressions of interest for the 2016 meeting have been received from Vietnam and New Zealand.

\section{J. M. Guss, IUCr Representative}

\subsection{European Crystallographic Association (ECA)}

As IUCr representative to the ECA I attended the regular winter meeting of the ECA Executive Committee (EC), Budapest, Hungary, 24-26 February 2012. The ECA President, S. García-Granda, opened the Committee's work by summarizing the matters arising from the Minutes of the ECA Executive Committee Meetings held at the Madrid Congress. The Irish Crystallographic Association, representing the interests of the crystallographic community in both the Republic of Ireland and Northern Ireland, was formed in 2011 and has applied to join the ECA as a National Member; this proposal was warmly commended by the Executive Committee for approval by the ECA Council to be held at ECM-27 in Bergen, Norway. The ECA Executive Committee consistently makes the effort to invite countries from the ECA region, namely Europe and Africa as well as the 
Middle East, that are not yet members of the ECA to join the Association, either as Members or perhaps as Observer Countries.

The activities of the Special Interest Groups (SIGs) are reviewed from year to year. The number of individual members registered with SIGs has increased significantly in the last year. Two thirds of SIGs/ General Interest Groups (GIGs) now have active web sites and one quarter have a mailing list. A new system of social and academic networking groups was introduced at ECM-25 and ratified by the ECA Council in Madrid. These GIGs follow similar constitutional rules as the SIGs. GIG1 - Young Crystallographers had already started to operate enthusiastically at ECM-25, ad interim, and at the Madrid Congress, where it was formally constituted. This GIG is organizing the Microsymposium How to ... at the ECM in Bergen. GIG2 - Senior Crystallographers is completing its formation, and is already preparing its opening session at ECM-27 in Bergen. The founding of a GIG for Teaching is emerging and others may be called into being in the future.

The ECA recognizes the strategic importance of the education of future generations of crystallographers at all levels. In the process of the establishment of a European Graduate School of Crystallography, an improved proposal for an Erasmus Mundus Master Course was submitted, which involves a collaboration of several European universities and companies, to the European Community Offices in Brussels. The ECA has for a long time enthusiastically and regularly provided financial support to schools within the ECA region. The ECA will support five conferences/workshops/schools in 2012. Whilst still being committed to giving regular support to these local initiatives, the ECA intends to promote a high-level European School (ECS), plans for which have been initiated by the Italian Crystallographic Association, for continuous, and rigorous, education in crystallography. The plan is that this ECS will be held annually in a different European country. This initiative will involve the ECA directly through an ad interim Sub-committee on Education (ECA$\mathrm{SE}$ ). The Executive Committee is working on the guidelines that will be available soon to all potential applicants for these European Crystallographic Schools. This proposal has been approved by the ECA Councillors.

After the representation of the Corporate Affiliate Members in the ECA Council was formalized in Madrid in the form of a CAM Councillor, A. Savill was elected by the CAMs. This formation has already led to improved guidelines about the requirements and recommendations for Commercial Exhibitions at ECMs. These guidelines, together with an improved version of How to Prepare and Submit a Bid to Host a Future ECM and Guidance for ECM Organizers, will assist future bidders to host and organize European Crystallographic Meetings (http://www.ecanews.org/Guidlines_ ECM.php). The ECA is very grateful to A. Savill as well as to A. J. Blake for their detailed assistance in these revisions.

The ECA is aware of the general economic climate and that this might be presenting hardship to crystallographers at all stages of their careers, as well as causing difficulties for some to attend an ECM. Thus the Executive Committee has launched a call for donations from those that can help other colleagues to attend the ECMs by contributing to their costs. It has been proposed to the ECA Council that these ECA Scholarships should be launched formally; these will be in addition to the existing ECA Student Bursaries for ECMs. Applicants have to have been an individual member for at least three years to qualify to apply for an ECA Scholarship to attend an ECM; detailed rules will be made available as soon as possible.

The ECA is enthusiastically supporting the IUCr initiative of the International Year of Crystallography to promote crystallography worldwide, and ECM-27 and ECM-28 have plans at an advanced stage. Indeed, the Chairs of the next ECMs, namely ECM-27 Bergen, Norway, 2012, ECM-28 Warwick, UK, 2013 and ECM-29 Rovinj, Croatia, 2015, presented progress reports to the Executive Committee. The decision on the venue of ECM-30 in 2016 will be made in Bergen by the ECA Councillors. The ECM-27 Bergen meeting is going to be a great scientific event. For example, D. Shechtman, Nobel Laureate in Chemistry 2011, will deliver a Plenary Lecture, accompanied by a special Microsymposium on Quasicrystals funded by the Nobel Foundation. There will also be a special Laue Centennial Lecture to be given by D. Schwarzenbach, which will commemorate the 100th anniversary of the discovery of X-ray diffraction by Laue, Friedrich and Knipping. There will also be the Max Perutz Prize and the Bertaut Prize Lectures. The sixth Max Perutz Prize of the European Crystallographic Association has been awarded to H. Fuess, Darmstadt, Germany. Professor Fuess is recognized for his outstanding contributions to structure research of functional materials such as zeolites, fuel cells and magnetic materials, the construction of scientific instruments at large-scale synchrotron and neutron facilities, and his skilled and enthusiastic service to crystallography in Europe and the broader international community. The Fifth Erwin Felix Lewy Bertaut Prize of the European Crystallographic Association (ECA) and European Neutron Scattering Association (ENSA) in 2012 has been awarded to P. V. Afonine from the Lawrence Berkeley National Laboratory, Berkley, USA. Dr Afonine is recognized for his notable work on the theoretical and methodological aspects of X-ray and neutron macromolecular crystallography and specifically has developed software to use neutron diffraction data in combination with or separately from X-ray diffraction data.

\section{E. Boldyreva, IUCr Representative}

\subsection{International Organization for Crystal Growth (IOCG)}

No formal meeting of the IOCG (http://www.iocg.org/) was planned or organized in 2011.

The IOCG President for 2010-2013 is R. Fornari (Germany), with Co-Vice-Presidents T. F. Kuech (USA) and E. Vlieg (The Netherlands), Secretary K. Kakimoto (Japan), and Treasurer V. Fratello (USA). The other members of the Executive Committee are H. A. Dabkowska (Canada), J. Derby (USA), T. Duffar (France), J. M. Garcia-Ruiz (Spain), Y. Mori (Japan), K. Roberts (UK), P. Rudolph (Germany) and A. Voloshin (Russia).

The connection with the IUCr Commission on Crystal Growth and Characterization of Materials (CCGCM) is evident, as T. F. Kuech (USA), K. Kakimoto (Japan), H. A. Dabkowska (Canada), T. Duffar (France) and J. M. Garcia-Ruiz are also members/consultants of the CCGCM.

The 17th International Conference on Crystal Growth and Epitaxy (ICCGE-17) will be held in Warsaw, Poland, 11-16 August 2013 [Chairs S. Krukowski (Poland), R. Fornari (Germany)]. Members and consultants of the CCGCM are strongly involved in the work of the Programme and Advisory Committees of this meeting.

For the first time, three symposia will be co-organized by members/ consultants of the CCGCM as IUCr representatives:

A. Moreno will co-chair symposium G03: Biological and Biogenic Crystallization;

K. Byrappa will co-chair G04: Industrial Crystallization;

T. Duffar will co-chair G07: Defect Formation/Elimination.

The 15th International School on Crystal Growth will be held in Gdansk, Poland, 4-10 August 2013, and will be chaired by W. Sadowski and E. Talik. E. Talik is also a consultant of the CCGCM. 
Detailed information about the conference and the school will be posted on the web sites http://science24.com/event/iccge17/ and http:// www.ptwk.org.pl/pol/documents/ISSCG-15-1.pdf, respectively.

The next IOCG General Assembly will take place in Warsaw, Poland, during ICCGE-17.

The European Network of Crystal Growth (ENCG) was formed at the end of 2010. One of the tasks of the ENCG is the organization of an European Conference on Crystal Growth (ECCG). ECCG4 will be held in Glasgow, UK, 17-20 June 2012, and will be chaired by K. Roberts. This is an important event, as the last European Conference on Crystal Growth was held more than 20 years ago. Many members and consultants of the CCGCM are involved in the organization of this conference.

National Associations for Crystal Growth were active in promoting crystal-growth science in their own countries as well as in collaborating in the organization of international events related to crystal growth. Some examples are listed below.

The 18th American Conference on Crystal Growth and Epitaxy in conjunction with the 15th US Biennial Workshop on Organometallic Vapor Phase Epitaxy (ACCGE-18/OMVPE-15) were held together in Monterey, California, USA, 31 July - 5 August 2011.

The Latin-American School of Crystallization and Crystallography, Florianopolis, Brazil, 13-25 November 2011.

German-Polish Conference on Crystal Growth (GPCCG) 2011, Frankfurt (Oder)/Slubice, 14-18 March 2011.

The 5th Asian Conference on Crystal Growth and Crystal Technology, Singapore, 26 June - 1 July 2011.

5th International Workshop on Crystal Growth Technology, Berlin, Germany, 26-30 June 2011.

\section{A. Zappettini, IUCr Representative}

\subsection{International Centre for Diffraction Data}

The Commission on Powder Diffraction maintains close links with the ICCD and also with the International X-ray Absorption Society (IXAS) (http://www.i-X-s.org/).

P. Whitfield, IUCr Representative

\section{Representatives on Other Bodies}

\subsection{IUPAC Interdivisional Committee on Terminology, Nomen-} clature and Symbols (ICTNS)

ICTNS continued its activities on behalf of IUPAC in reviewing and approving Technical Reports and Recommendations submitted to IUPAC for publication in Pure and Applied Chemistry, and also for approving, on behalf of IUPAC, publications emanating from international bodies on which IUPAC has representation. In 2011, there were none of specific interest for crystallography.

\section{A. Authier, IUCr Representative}

\subsection{International Council for Scientific and Technical Information (ICSTI)}

ICSTI offers a unique forum for interaction among organizations that create, disseminate and use scientific and technical information. ICSTI is a scientific associate of ICSU, the International Council for Science. ICSTI's mission cuts across scientific and technical disciplines as well as international borders, to give member organizations the benefit of a truly global community. ICSTI increasingly liaises with CODATA with conferences and workshops, for example.
The winter ICSTI Conference in February 2011 was held in Redmond, Washington, USA, at the Headquarters of the Microsoft Corporation on the topic Multimedia and Visualization Innovations for Science (http://www.icsti.org/spip.php?article159). Presentations were made by technology, science and information professionals across the broad spectrum of academia, government, business and industry, and included crystallography and structural science in a talk by R. Hanson on Jmol (see http://prezi.com/khaylnfjmbls/jmol-icsti/).

The summer ICSTI Congress for 2011 was held in Beijing, People's Republic of China. The IUCr could not be represented. The Congress was hosted by ISTIC, the Institute of Scientific and Technical Information of China, and the theme of the meeting was Upgrading Information to Knowledge.

The winter ICSTI Conference for February 2012 is to be on Delivering Data in Science, organized by DataCite, and to be held at the ICSU offices in Paris, France.

In addition to the two conference events per year, a further special highlight has become ICSTI's Technical Activities Coordinating Committee (TACC) Meeting within the suite of ICSTI general meetings. The TACC brings together a wide-ranging set of projects and initiatives. Highlights have previously included the South Korean technical development project for accessing scientific journal literature from the iPhone and, more recently discussed, the ORCID initiative to establish a universal 'researcher identification number', which would aid the submission of scientific articles for publication, for example.

J. R. Helliwell acknowledges with gratitude the close collaboration with IUCr's delegate to CODATA, Brian McMahon, and also with the IUCr Managing Editor, Peter Strickland.

\section{J. R. Helliwell, IUCr Representative}

\subsection{International Council for Science (ICSU)}

A thorough presentation of ICSU and its role as science coordinator was given in the 2008 Annual Report of the IUCr Executive Committee [Acta Cryst. (2010), A66, 98-126]. The membership of ICSU has grown steadily in the past years so its membership in early 2012 comprises 31 scientific unions and 120 national members covering 140 countries; in addition there are 22 scientific associates of ICSU. It has been the tradition that the Immediate Past President represents the IUCr at ICSU and it was in this role that I attended the 30th ICSU General Assembly, Rome, Italy, 26-30 September 2011.

The day prior to the opening of the General Assembly was dedicated to Open Forum meetings for the members of the scientific unions and members of the national committees. It was a good opportunity to meet representatives of the other scientific unions and discuss issues of mutual interest, such as candidates for ICSU's new Executive Committee, and the balance of science and administrative issues on the agenda of the General Assembly.

An important point on the agenda concerned the results from the implementation of ICSU's first strategic plan 2006-2011. The focus of this plan had been on international research collaboration, science for policy and the Universality of Science. A number of global initiatives were initiated and much emphasis has been placed on assurance of access to data and information. As a result of the plan, Regional Offices had been established in developing parts of the world that should stimulate interactions between member countries. A special ad hoc group has been established to define ICSU's future role in relation to science education; the IUCr had been represented by G. Chapuis in this group. 
ICSU's Strategic Plan II 2012-2017 was presented at the General Assembly and a number of initiatives related to the plan were approved; these all match the overall goal of strengthening international science for the benefit of society and many of the goals are the same as in the first strategic plan. Global sustainability is one of the key words in the plan and environmental issues play a central role.

The Committee on Freedom and Responsibility in the Conduct of Science (CFRS) had been established in 2006. One of the key elements of the Committee's work had been an analysis of the Principle of Universality enshrined in ICSU's statutes. The revised wording formulated by CFRS caused animated discussions in the General Assembly; however, a slightly altered formulation was approved unanimously the following day.

An ad hoc group had been created at the last General Assembly to look at the issue of weighted voting. Some national members expressed the concern that weighted voting could accentuate the differences between national members owing to their wealth. It was emphasized that weighted voting would only be applied to financial issues and the General Assembly approved the proposal and the subsequent change in statutes.

Poster Expresso sessions, where participants in the General Assembly gave short ( $2 \mathrm{~min}$ ) presentations about their organization, were included in the agenda for the first time. They served as a good break in the agenda and stimulated contacts among the delegates.

Finally, the General Assembly concluded with the election of the new members of the Executive Committee. The President of ICSU for 2011-2014 is Yuan Tseh Lee.

\section{S. Larsen, IUCr Representative}

\subsection{ICSU Committee on Data for Science and Technology (CODATA)}

New CODATA members and new cooperation agreements. Two new Supporting Organizations joined CODATA during 2011: the National Archives and Records Administration, and the Computer Network Information Center, Chinese Academy of Sciences. Additionally, CODATA committed to future collaboration with two organizations through memoranda of understanding: the International Program Office on Integrated Research on Disaster Risk, and the International Society for Digital Earth.

Task Group activities. The Task Group on Earth and Space Science Data Interoperability had two working meetings during the year: in Uglich, Russia, during the International Workshop on Artificial Intelligence in the Earth's Magnetic Field Study (January); and in Melbourne, Australia, within the framework of the IUGG XXV General Assembly and the 12th IAGA Scientific Assembly (June/ July).

The Task Group CODATA EU Global Information Commons for Science Initiative held a planning meeting in Paris, France, during May for the First Global Thematic Conference of the International Association for the Study of the Commons (IASC) in September 2012.

The Task Group WEAR Anthropometric Data and Engineering met in Adelaide, Australia, during February.

The Task Group on Fundamental Physical Constants announced the public release of the 2010 Least-Squares Adjustments of the Values of the Fundamental Constants (http://physics.nist.gov/cuu/ Constants/index.html).

The Task Group Preservation of and Access to Scientific and Technical Data in Developing Countries organized a joint project Workshop on Open Knowledge and Data Environment for Innova- tive Research, Education and Society during July in Ulaanbaatar, Mongolia.

The Task Group on Data Citation Standards and Practices held a substantial workshop on Developing Data Attribution and Citation Practices and Standards in Berkeley, CA, USA, during August, in tandem with the DataCite Conference 2011.

The Task Group on Data at Risk participated in the meeting Ensuring Long-Term Preservation and Adding Value to Scientific and Technical Data, in Toulouse, France (November), and at the 7th International Digital Curation Conference (Bristol, UK, December).

CODATA - 45 years on. A special high-level one-day International Symposium to commemorate CODATA's 45th Anniversary took place in Beijing, People's Republic of China, on 30 October. The event was entitled Data Intensive Science and Discovery - CODATA 45 Years, and brought together CODATA's members and contributors to look back on the international organization's history as well as discussing the next phase of its evolution. The IUCr was represented at this event by Xiao-Dong Su, Chair of the Commission on Biological Macromolecules.

I acknowledge the most useful document CODATA Report of Activities 2011, posted on the CODATA web site at http://www. codata.org, in compiling this summary.

\section{B. McMahon, IUCr Representative}

\subsection{ICSU Committee on Space Research (COSPAR)}

The main objective of COSPAR (http://cosparhq.cnes.fr/) is to promote international collaboration in scientific research in space, with an emphasis on the exchange of results, information and opinions. Developing world standards for the space environment and its protection requires the creation of national and international organizations and specialist working groups.

COSPAR acts mainly as a body responsible for organizing biennial Scientific Assemblies, and the year 2011 was devoted to organizing the next meeting, the 39th COSPAR Assembly, to be held in Mysore, India, 14-22 July 2012. The previous Assembly was held in Bremen, Germany, 18-25 July 2010.

The majority of COSPAR's activities are related to space topics (astronomy, astrobiology, geophysics, atmosphere studies, investigation of natural and artificial ecosystems, as well as space travel). The most interesting COSPAR division for the IUCr is the Scientific Commission on Materials Science in Space (MSS Commission G), chaired by V. Shevtsova (Belgium) and co-chaired by S. Amiroudine (France), W.-R. Hu (People's Republic of China) and S. Yoda (Japan). This Commission coordinates fundamental experiments in materials and fluid sciences performed in space, utilizing reduced gravity for their objectives. This approach helps to understand emerging fields by recommending promising avenues for future research. It also facilitates exchanges of information on relevant scientific subjects.

The International Year of Crystallography (IYCr) could provide an opportunity for greater collaboration between the $\mathrm{IUCr}$ and COSPAR. At the Mysore Assembly the IUCr representative will make a preliminary announcement to the Council about the IYCr. I plan to present a more detailed summary in Moscow in 2014, the actual IYCr. I am also planning to submit information about IYCr for publication in Space Research Today. Advances in Space Research is an official journal of COSPAR. It covers all areas of space research including, but not limited to, space studies of the earth's surface, meteorology, climate, fundamental physics in space, materials physics in space, space debris, weather and earth observation of space 


\section{international union of crystallography}

Table 1

Income and Expenditure Account (in Swiss Francs) for the year ended 31 December 2011.

2011

2010

Income

Membership subscriptions

165106

153000

Sales

Journals, back numbers and single issues

Book

3574108

Open Access Grant

Investment income

$\begin{array}{lr}\text { Income from investments } & 73673\end{array}$

73673
1123

(Loss)/Profit on sale of investments

Other income

Royalties and copyright fees

Total income

Expenditure

Journals

Publication costs

Editorial expenses

Technical editing

1265121

Subscription administration

Books

Publication costs

Editorial expenses

Technical editing

Newsletter

Publication costs

President's Fund and other Grants and Young Scientists' support

23179

226936

General Assembly and Congress costs

92922

483178

7699

182705

Editors' meetings

STAR/CIF

Promotion

Subscriptions paid

Visiting Professorship Programme

Administration expenses:

Honorarium to General Secretary and Treasurer

Audit and accountancy charges

Legal and professional fees

Travelling expenses

Bank charges

9614

56575

7975

14864

5759

Executive Secretary's office:

Salaries and expenses

Travel expenses of IUCr Representatives on other bodies

Commission (income)/expenses

Sponsorship of meetings

IUCr/FIZ agreement

Bad debts

Depreciation

289389

1226

7612

(15 457)

7498
94787

673582

14219

12542

538906

713404

11400

5048

93028

Total expenditure 


\section{international union of crystallography}

Table 1 (continued)

2011

Surplus of income over expenditure (before realized exchange losses)

Realized fluctuations in rates of exchange

Exchange movement on trading activities

Surplus/(deficit) of income over expenditure (after realized exchange losses)

Movement in market value of investments in year

Unrealized fluctuation in rates of exchange

Exchange movement on trading activities

Investment activities

(14 608)

Total recognized gains/(losses) relating to the year

Opening fund accounts at 1 January 2011

Closing fund accounts at 31 December 2011

2010

\begin{tabular}{|c|c|c|}
\hline 139954 & & 557505 \\
\hline (71 566) & & (161 625) \\
\hline 68388 & & 395880 \\
\hline (53 250) & & 198698 \\
\hline 15138 & & 594578 \\
\hline & $(68593)$ & \\
\hline 28260 & $(246259)$ & $(314852)$ \\
\hline 43398 & & 279726 \\
\hline 4658722 & & 4378996 \\
\hline 4702120 & & 4658722 \\
\hline
\end{tabular}

All the income and expenditure related to continuing activities. Historic cost results would only differ from above by the profit on sale of investments. Separate Statements of Total Recognized Gains and Losses and Reconciliation of Movements in the Fund Account are not given, as the information is incorporated in the above.

phenomena. ASR also includes the COSPAR's Information Bulletin, Space Research Today.

COSPAR's President for the period 2010-2014 is G. Bignami (Italy) and the Vice-Presidents are R. Lin (USA) and J. Wu (People's Republic of China). Members of the Bureau are: I. S. Batista (Brazil), K.-H. Glassmeier (Germany), A. Jayaraman (India), S. Sasaki (Japan), J.-P. St-Maurice (Canada) and L. Zelenyi (Russia).

COSPAR co-sponsored meetings in 2011 were as follows:

Advanced Land Surface Characterization, Cape Town, South Africa, 10-20 October 2011.

Data Analysis of the XMM-Newton, Chandra and Suzaku X-ray

Missions, San Juan, Argentina, 25 July - 5 August 2011.

Remote Sensing of Atmospheric Aerosols and Their Impacts, Greater Noida, India, 2-16 January 2011.

UN/Nigeria Workshop on the International Space Weather Initiative (ISWI), Abuja, Nigeria, 17-21 October 2011.

URSI/COSPAR International Reference Ionosphere Workshop,

Hermanus, South Africa, 10-14 October 2011.

IAU Symposium 286: Comparative Magnetic Minima: Characterizing Wuiet Times in the Sun and Stars, Mendoza, Argentina, 3-7 October 2011.

New Technologies for Future Space Astronomy Missions, Cape Town, South Africa, 5-6 October 2011.

28th International Symposium on Space Technology and Science, Ginowan City, Okinawa, Japan, 5-12 June 2011.

IX Latin-American Conference on Space Geophysics, Puntarenas, Costa Rica, 5-10 April 2011.

International Earth-Based Research Program as a Stepping Stone for Global Space Exploration Workshop, Washington, DC, USA, 2-4 March 2011.

H. A. Dabkowska, IUCr Representative

\section{Finances}

Extracts from the full financial statements, namely the Income and Expenditure account, Balance Sheet and Summary of Fund
Accounts, are given in Tables 1,2 and 3, respectively. ${ }^{\mathbf{1}}$ For comparison, the figures for 2010 are provided in italics. The accounts are presented in CHF.

The ICSU exchange rates, based on the official UN rates, have been used in the preparation of these accounts. As a consequence of the many fluctuations in exchange rates during the year, the following procedure has been adopted for the accounts. Assets and liabilities in currencies other than CHF at 31 December 2011 have been translated into $\mathrm{CHF}$ in the balance sheet at the rate operative at that date. For the income and expenditure accounts, transactions have been translated into CHF by applying the rates appropriate to the individual dates of these transactions. As a consequence of the fluctuation in exchange rates, overall an apparent loss has arisen on the assets of the Union, in terms of CHF, amounting to CHF 43 306. In the accounts this loss has been assigned as a 'Realized loss' (CHF 71 566) and 'Unrealized gain' (CHF 28 260). The loss attributable to investment activities has been assigned to the General Fund and the overall loss attributable to trading activities has been divided amongst the fund accounts in direct proportion to the balances on these accounts at 31 December 2011. It should be noted that this overall loss in CHF is not a real loss of money, but rather a loss on paper resulting from the accounts being expressed in CHF.

Investments are noted in the balance sheet at their market value at 31 December 2011.

The balance sheet shows that the assets of the Union, including the loss resulting from fluctuations in rates of exchange, have increased during the year, from CHF 4658772 to CHF 4702 120. The movement in market value of the investments was CHF -53250 in 2011 (CHF 198698 in 2010).

The following transfers were made from the Journals Fund: CHF 25000 to the Publications and Journals Development Fund; CHF 150000 to the Research and Education Fund; CHF 100000 to the

\footnotetext{
${ }^{1}$ The full audited accounts are available from the IUCr electronic archives (Reference ES0397). Services for accessing these data are described at the back of the journal.
} 
Table 2

Balance sheet (in Swiss Francs) as at 31 December 2011.

\begin{tabular}{|c|c|c|c|c|}
\hline & 2011 & & 2010 & \\
\hline \multicolumn{5}{|l|}{ Fixed assets } \\
\hline Tangible fixed assets & & 43861 & & 52746 \\
\hline Investments at market value & & 2390156 & & 2458959 \\
\hline \multicolumn{5}{|l|}{ Current assets } \\
\hline Stock & & 135659 & & 93829 \\
\hline Cash at bank and in hand & & & & \\
\hline Debtors, accrued income and payments in advance & & 513951 & & 1070171 \\
\hline Subscriptions due from Adhering Bodies & & 13162 & & 5500 \\
\hline Total current assets & & 2793303 & & 2552381 \\
\hline
\end{tabular}

Table 3

Summary of Fund Accounts (in Swiss Francs) as at 31 December 2011.

\begin{tabular}{|c|c|c|c|c|c|c|c|}
\hline & \multirow[t]{2}{*}{$\begin{array}{l}\text { As at } \\
\text { 1 January } 2011\end{array}$} & \multirow[t]{2}{*}{$\begin{array}{l}\text { Transfers } \\
\text { between } \\
\text { funds }\end{array}$} & \multirow[t]{2}{*}{$\begin{array}{l}\text { (Deficit)/ } \\
\text { surplus of } \\
\text { income over } \\
\text { expenditure } \\
\text { for the } \\
\text { year }\end{array}$} & \multirow[t]{2}{*}{$\begin{array}{l}\text { Decrease in } \\
\text { market } \\
\text { value of } \\
\text { investments }\end{array}$} & Fluctuations & $\mathrm{xchange}$ rates & \multirow[t]{2}{*}{$\begin{array}{l}\text { Balance } \\
\text { at } 31 \text { December } \\
2011\end{array}$} \\
\hline & & & & & Trading & Investments & \\
\hline \multicolumn{8}{|l|}{ Fund accounts } \\
\hline General Fund & $(1756091)$ & - & (297 548) & $(53250)$ & 12741 & (14 608) & $(2108756)$ \\
\hline Publications and Journals Development Fund & 969060 & 25000 & 1625 & - & $(6021)$ & - & 989664 \\
\hline Research and Education Fund & 947915 & 150000 & (135 721) & - & $(5819)$ & - & 956375 \\
\hline Ewald Fund & 504628 & 50000 & (35 392) & - & (3 140) & - & 516096 \\
\hline Newsletter Fund & 9421 & - & $(60073)$ & - & 306 & - & $(50346)$ \\
\hline \multirow[t]{2}{*}{ General Assembly and Congress } & 319305 & 100000 & $(127052)$ & - & $(1767)$ & - & 290486 \\
\hline & 4658722 & - & 139954 & $(53250)$ & $(28698)$ & $(14608)$ & 4702120 \\
\hline
\end{tabular}

General Assembly and Congress Fund; and CHF 50000 to the Ewald Fund.

The following comments refer to figures in the full accounts.

The General Fund account shows a deficit of CHF 297548 , as compared with a deficit in 2010 of CHF 303 856. The administrative expenses were CHF 390072 in 2011 as compared with CHF 391282 in 2010. Of this amount, CHF 170778 was charged to the publications of the Union.

The expenses of the Union Representatives on other bodies were CHF 7205. The cost of the Finance Committee meetings held in 2011 was CHF 9617, while the Executive Committee meetings cost $\mathrm{CHF}$ 72 446. The income from the IUCr/Fachinformationszentrum agreement (to provide low-cost copies of the Inorganic Crystal Structure Database) was CHF 15 457. The subscriptions from Adhering Bodies were CHF 164000 . Interest on bank accounts and investments credited to the General Fund was CHF 74797.

Grants totalling CHF 38277 were paid from the President's Fund in 2011.

The Journals Fund account for 2011 shows a surplus of CHF 900129 before the transfer of CHF 325000 to the other fund accounts, as compared with a surplus of CHF 1132016 in 2010 before the transfer of CHF 410000 to the other fund accounts.

The cost of the technical-editing office has been divided between the Journals Fund and the International Tables Fund in percentages based on the staff time spent on each publication. The technical-editing costs for the Journals Fund were CHF 1262406 as compared with CHF 13254614 in 2010. The Journals Fund has also been charged with administration expenses as in previous years as shown in the General Fund.

The International Tables account shows a deficit of CHF 67737 , as compared with a surplus of CHF 25261 in 2010. The net sales income was CHF 92913 in 2011 as compared with CHF 208783 in 2010. From January 2010 the publisher changed from Springer to Wiley.

The cost to the Union of producing the Newsletter in 2011 was CHF 60073.

In the Publications and Journals Development Fund account, the computing and promotion expenses are divided between the General Fund, the Journals Fund and the International Tables Fund. STAR/ CIF costs, Special Issue costs, journal grants and web input costs are also charged to the Publication and Journals Development account. 


\section{international union of crystallography}

From 2000, costs associated with the Crystallographic NeXus Project to provide CD-ROMs (containing crystallographic software and web material) free of charge to developing countries have been charged to this Fund. In 2011, CHF 4521 was provided from this Fund as journal subsidies in connection with the Journal Grants Fund, which was set up to assist institutions that have difficulties in meeting the full subscription price. CHF 123179 for financial support to young scientists, to enable them to attend scientific meetings sponsored by the Union, was charged to the Research and Education Fund.

In 2007 a General Assembly and Congress Fund was established so that the costs associated with the General Assembly and Congress could be spread over the triennium. In 2011 this Fund incurred expenses totalling CHF 127052 and received a transfer of $\mathrm{CHF}$ 100000 from the Journals Fund. 